\title{
Direct development in the Australian myobatrachid frog Metacrinia nichollsi from Western Australia
}

\author{
Marion Anstis \\ 26 Wideview Rd, Berowra Heights, New South Wales 2082, Australia. Email: frogpole@tpg.com.au
}

\begin{abstract}
The development of the myobatrachid frog Metacrinia nichollsi from southwestern Australia is described. Metacrinia nichollsi and the related myobatrachid direct developing species Myobatrachus gouldii and Arenophryne rotunda all differ from Eleutherodactylus coqui in that their forelimbs develop internally and emerge later, and they do not have a keratinised egg tooth. Eggs of $M$. nichollsi were found deposited beneath leaf litter on dry sand not associated with water and embryonic development is completed entirely within the jelly capsule over a period of more than two months. Observations on a predatory nematode worm are noted.
\end{abstract}

Keywords: Australia, frog, embryo, endotrophic, predatory nematode

\section{INTRODUCTION}

Endotrophic anurans derive all their developmental energy from vitellogenic yolk or other parentally produced material (Thibaudeau and Altig 1999), unlike typical exotrophic anuran larvae that need to feed to gain energy post hatching. In taxa with direct development, all embryonic development takes place within the jelly layers of the egg until a froglet hatches; there is no hatched free-living embryo or tadpole. In broad reviews of Australian anuran life-histories, Tyler (1985) and Roberts (1993) included the Australian endotrophic genera Assa, Kyarranus, Philoria, Rheobatrachus and the Geocrinia rosea group as direct developers. These genera, however, have mostly been classified in three different endotrophic guilds by Altig and Johnston (1989), but some genera are added here to the nidicolous guild as follows: nidicolous - Philoria, plus Bryobatrachus and Geocrinia rosea group; exoviviparous - Assa; paraviviparous - Rheobatrachus. None of these are in the specific category of direct developers like the microhylids Cophixalus and Austrochaperina and the myobatrachids Arenophryne and Myobatrachus. Direct development has arisen in at least nine anuran families around the world, showing its propensity for occurrence in distantly related groups and similarly, the nidicolous guild of endotrophs occurs in at least seven families (McDiarmid and Altig 1999). In this paper, the Australian myobatrachid Metacrinia (closely related to Myobatrachus and Arenophryne) is also confirmed as an additional direct developer.

Direct developing embryos differ in many ways from both exotrophic tadpoles and from other guilds of endotrophs (Altig and Johnston 1989), and our knowledge of the taxa with this developmental mode typically is lacking in detail. Much of the available information is based on three genera with a specific concentration on the South American frog Eleutherodactylus coqui (Thibaudeau and Altig 1999; Altig and Crother 2006). Anstis et al. (2007; Myobatrachus gouldii and Arenophryne rotunda) is the only study involving Australian taxa, but provides little information on living specimens.

Metacrinia nichollsi is a small myobatrachid frog restricted to forests in southwestern Australia, including a population in the Stirling ranges (Tyler et al. 2000). Originally described by Harrison (1927) as Pseudophryne nichollsi, it was identified as a possible variant of $P$. bibronii by Parker (Barbour and Loveridge 1929). The monotypic genus Metacrinia was later erected for this frog by Parker (1940), but Blake (1973) proposed the species be referred to Pseudophryne and that the genus Metacrinia be suppressed. More recently Maxson and Roberts (1985) found that Metacrinia and Pseudophryne are most closely related to the lineage giving rise to Myobatrachus and Arenophryne, and retained the genus Metacrinia as distinct from Pseudophryne. Further work by Read et al. (2001) places Metacrinia as the sister clade to Myobatrachus and Arenophryne, while Frost et al. (2006) place Metacrinia and Arenophryne in the same clade, with Myobatrachus being more distantly related.

Little is known of the breeding biology of Metacrinia, as observations of embryonic material have been very limited. They live in areas of the highest rainfall in southwestern Australia and frogs are found mainly among leaf litter or under rotting logs in Karri (Eucalyptus diversicola) and Jarrah ( $E$. 
marginata) eucalypt forests away from water. They can occur in association with nests of the bull ant Myrmecia regularis (Barbour and Loveridge 1929; Glauert 1945). Driscoll (1998) observed males calling perched in bushes up to $50 \mathrm{~cm}$ above ground, and they also are known to call from secluded sites (such as beneath leaf litter) on the ground, as well as from burrows made by other frog species. Driscoll even reports a female calling (with a different type of call) from a shallow burrow. Apart from one clutch found with two adults beneath a log near Pemberton on 17 March 1929 by W. S. Brooks (Barbour and Loveridge 1929) and another by B. Knight who found a frog with a clutch at Springfield near Pemberton on 18 March 1943 (Glauert 1945), no other embryonic material has been previously reported. In his early field observations (March 1927), Brooks noted that the clutch contained "a pile of 25-30 eggs each about $3 / 16$ inch $[4.8 \mathrm{~mm}]$ in diameter". This would have been the diameter of the external jelly capsule, as the developing embryos were not studied with a microscope. Brooks states that embryos were active with obvious eyes and the capsules appeared to have been "rolled in dust to retard evaporation." He kept them alive for more than six weeks before they died (within their capsules), without reporting further observations on their development (Barbour and Loveridge 1929).

Based on these limited early observations, Glauert (1945) stated that "eggs are laid in a hollow under a log or stone, where they are guarded by the parent" and "the eggs develop directly without any tadpole stage." Direct development in Metacrinia has been considered probable as calling males are not found near or associated with water, and the species is closely related to the direct developing $A$. rotunda and $M$. gouldii (Tyler 1976; Maxson and Roberts 1985). Although some juvenile froglets of Metacrinia have been found under leaf litter in forest not near water (D. Edwards, pers. comm.), no other early material was available for study.

The recent collection of a single clutch has enabled a detailed description of the live development of this species (Table 1; Figures 1-5). Comparisons are made between the development of Metacrinia and A. rotunda and $M$. gouldii from Anstis et al. (2007), and with the well-known South American E. coqui. Observations of an attack on one embryo by a predatory nematode worm are given.

\section{MATERIALS AND METHODS}

A single, freshly laid clutch of 15 eggs was collected by $M$. Dziminski at Coalmine Beach Caravan Park, $4 \mathrm{~km}$ west of Walpole on the southern coast of Western Australia on 26 March 2006. Sand and soil were removed from the egg jellies with forceps and a fine sable brush moistened with water. Initially the clutch was not separated, but after two days, three embryos at the bottom of the clutch were found dead and were removed in their capsules with fine scissors. The rest of the eggs were laid out in a single layer (and some separately) on moistened filter paper in a partly covered petri dish kept in a darkened area during the day. As the eggs were not found in association with water in the field, they were only moistened twice a day with a drop of rainwater over each.

To avoid distortion caused by the jelly capsule in photographs, it was necessary to immerse embryos in water for a few minutes to see them more clearly through the jelly. This was done once a day for the first four weeks but reduced to once every two or three days for a shorter time during later development after two embryos appeared to develop cedema. Apart from the first two days before the clutch was separated, measurements of live and preserved embryos were taken with an ocular micrometer attached to a Wild M5 stereoscopic microscope while embryos were immersed in water (Appendix 1 and 2). Individual specimens at various stages were first anaesthetised in $1 \%$ chlorbutol solution and then preserved in Tyler's fixative (1962) diluted by one third. Material was catalogued in the Western Australian Museum (WAM R133194).

The single clutch of 12 eggs collected at Springfield, near Pemberton by B. Knight in 1943 (WAM R8543/44) was examined and comparisons with the present clutch were made. Photographs of live specimens (Figures 2-5) were taken with a Nikon D70 and $60 \mathrm{~mm}$ macro lens. To present images more clearly, waste yolk material circulating inside the vitelline membrane from stage 5 that obscured parts of the embryo was edited out in all photographs except Figure $4 \mathrm{E}$ and $\mathrm{F}$, and also Figure $2 \mathrm{H}$, in which the yolk released as a direct result of the worm attack was also retained. Drawings of some stages of preserved specimens were made with a camera lucida attached to the microscope (Figure 1). Preserved specimens were stained in a very weak solution of crystal violet before drawing.

The staging system of Townsend and Stewart (1985) for E. coqui was used, as this is the only direct developing species for which an appropriate staging table exists. As this system was devised purely for use in the field without a microscope, it only stages embryos based on a combination of more obvious morphological, behavioural and pigmentation features visible macroscopically such as cleavage furrows (stage 1), blastopore formation to neural folds (stage 2), neural tube (stage 3), first limb bud development (stage 4 ) etc., but numerous other features are combined in the classification of each of the fifteen stages. To provide more information, and to set a basis for future 
A

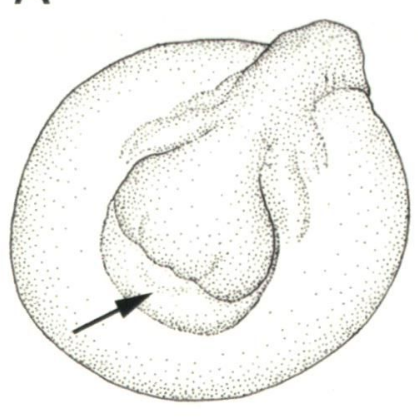

B

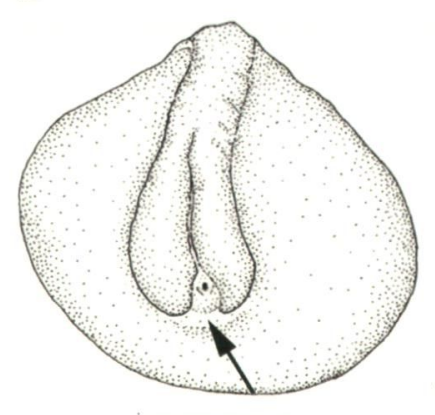

C

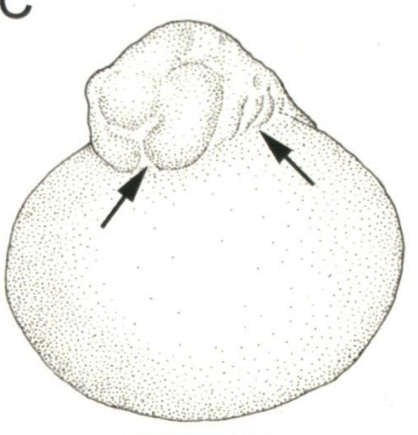

D

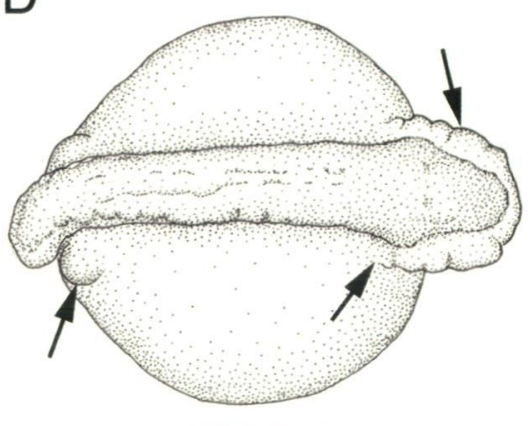

F

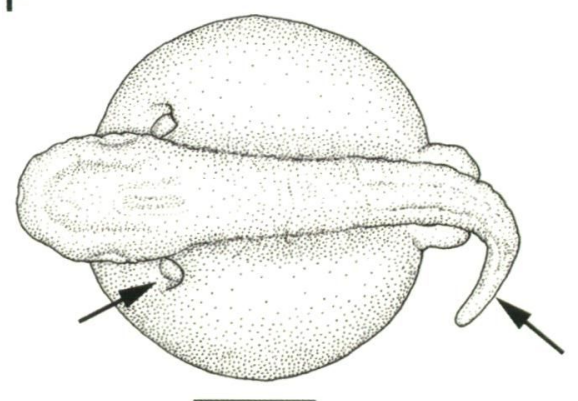

$\mathrm{H}$

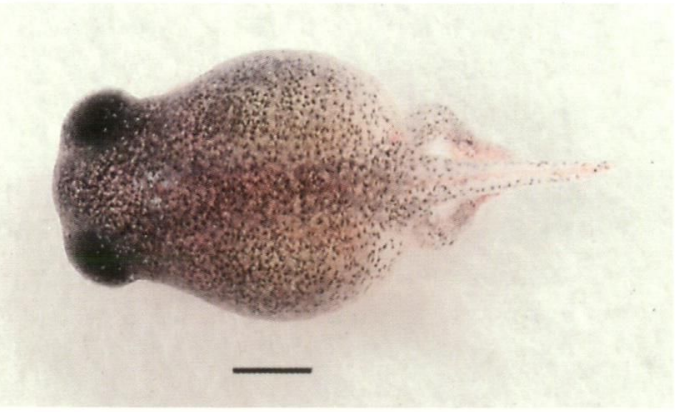

E

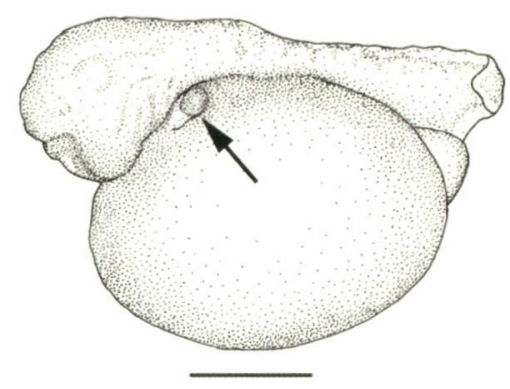

G

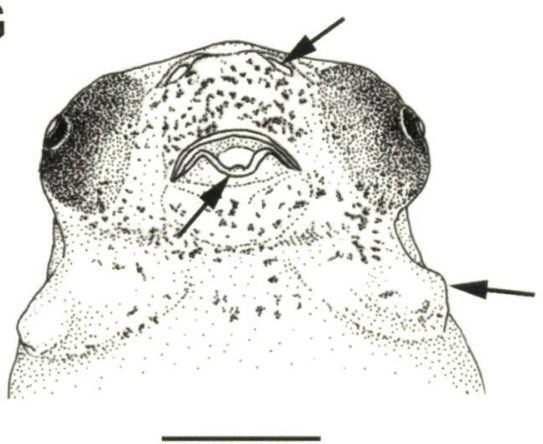

I

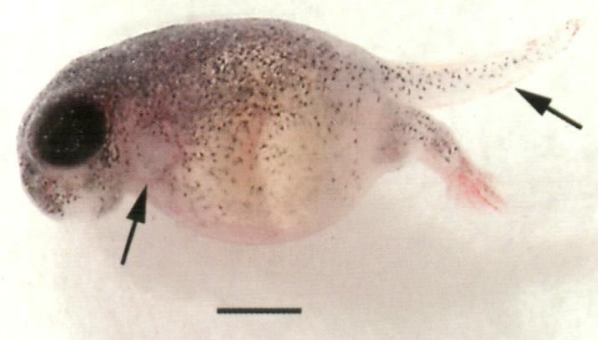

Figure 1 Stages 3-5 and 10 (Townsend and Stewart 1985) of Metacrinia nichollsi. A, stage 3, arrow = ridge below stomodaeal depression; B, stage 3, arrow = grooved tail bud and vent; C-D, stage 4, arrows = gill arches and vertical groove in lower jaw (C), gill arches and bulges flanking sides of stomodaeal depression, slight forelimb bud swelling and hind limb bud (D); E-F, stage 5, arrows = slit in opercular fold over forelimb bud, and tail bud; G, stage 10, arrows = small conical ridge on lower lip with tongue above, naris and forelimb bulge; H-I, stage 10, œdematous embryo removed from jelly layers, arrows = forelimb bulge and extended tail. Scale bar represents $1 \mathrm{~mm}$. 
descriptions, additional detail (observable with the aid of a microsope) on each stage available for Metacrinia, are given here. Comparative references are made to the hind limb development as staged by Gosner (1960) to provide a known point of reference and facilitate description of limbs. To better simulate environmental conditions, temperature was not controlled and ranged between $10-19^{\circ} \mathrm{C}$ and occasionally up to $29^{\circ} \mathrm{C}$ (mean $18^{\circ} \mathrm{C}$ ) during the 68 day development period in the laboratory.

\section{RESULTS}

The eggs in the single clutch preserved with the adult frog in 1943 (WAM R8543/44) were covered with fine sand. Eleven eggs were firmly adherent and one was separated. The embryos were at stage 3 and nonpigmented, with an indistinct head region discernable and small swelling in the tail bud region. The neural tube was closed and a slight stomodaeal depression was visible, but embryos were in poor condition after over 50 years in ethanol. Mean external dimensions (length $\mathrm{x}$ width) of four eggs was $3.8 \times 3.4 \mathrm{~mm}$ (range $3.6 \times 3.4$ to 3.9 $x 3.5 \mathrm{~mm}$ ) and four embryos removed from the jelly capsule measured $2.8 \times 2.4 \mathrm{~mm}$ (range $2.8 \times 2.2$ to $2.9 \times 2.6 \mathrm{~mm}$ ). The male adult frog found with this clutch was sexed by dissection.

The recent freshly laid clutch of eggs was found in dry coastal woodland on the grounds of a caravan park about $50 \mathrm{~m}$ from a large saltwater bay at Walpole. The eggs were under slightly moist leaf litter on dry, powdery grey sand with an adult male frog sitting on top of the clutch and a spent female nearby. Air temperature at $2000 \mathrm{~h}$ was $11.3^{\circ} \mathrm{C}$ and ground temperature within the nest site was $15.4^{\circ} \mathrm{C}$. Recent early autumn weather was mostly dry, and the annual cooler wet season usually begins in this region during May-June. The clutch was transported to the laboratory and embryos had reached stage 2 when first examined with a microscope about six days after they were laid. Embryos were difficult to see prior to cleaning because the jelly surfaces were mostly covered with sandy soil and the eggs were in a pile of up to three layers (Figure $2 \mathrm{~A}, \mathrm{~B}$ ).

Dimensions of the clutch were $21 \mathrm{~mm}$ long, 16.5 $\mathrm{mm}$ wide and $15 \mathrm{~mm}$ high and the clear jelly capsules were strongly adherent and could not be separated without being cut apart. The jelly was slightly viscous and the entire clutch wobbled when moved. Three embryos which had died prior to stage 3 , were removed from the centre of the bottom layer of the clutch. After this, the clutch was cut apart with fine scissors and laid in a single layer, with most still adjoining and some separate. After one week, all jelly capsules were individually separated and spread out over the filter paper.
Each embryo is surrounded by two jelly layers. The outer narrower layer (Figure 2I, bar at A), is thinner, much denser and with more visible structure than the inner layer (Figure 2I at B), and seems to be composed of two zones. Fine, parallel lines in the inner zone (Figure $2 \mathrm{I}$ at $\mathrm{C}$ ) of the outer layer suggest additional structure.

\section{Development}

As the spent female was still with the clutch when it was collected on 26 March, this date is taken as day 1 , although it was not possible to initially examine embryos with the microscope at this time. The first day of observations in the laboratory was day 6 when the embryos were at stage 2 (Townsend and Stewart 1985).

Observations on the primary developmental features of the head and body, limbs, eyes, tail, endolymphatic calcium deposits (ECD), pigmentation and behaviour are provided in Table 1 (see Figures 1-5), with additional detail provided in the text for the development of the mouth, ECD, nares, gut, vent and size during development. Some T\&S (Townsend and Stewart 1985) stages span 1-2 days, while others extend over three or more days. Developmental descriptions are based on major morphological characters visible in live embryos using a microscope without dissection from stages $2-15$, supported by additional observations on the preserved, stained specimens. Stage 2 embryos were only observed and photographed while the entire clutch was out of water and still partly obscured by soil particles (Figure 2 A, B).

\section{Mouth}

The mouth begins as a shallow stomodaeal depression with a slight ridge below, at stage 3 (Figure 1A); a broad bulge develops on either side of this depression during stage 4 as the stomodaeum deepens, broad jaw ridges are visible and the lower jaw ridge is medially divided by a vertical groove (Figure $1 \mathrm{C}$ ). The mouth slit begins to extend to each side of the head during stages 4 to 5 and is deepest in the centre, then towards each side of the head it becomes narrower and curves downwards. During stage 6, the upper and lower jaws are formed, the vertical groove in the lower jaw closes, and a small pouch-like chin area forms in the centre below the lower lip. By stage 7 , the jaws are more defined, and there is a distinct chin. By stage 8 , the upper lip projects forwards slightly, the mouth slit extends partway around each side of the head in lateral view, and the jaws are well formed. By stage 9, the tongue is present and the lips are more defined and curve downwards at each side (anterior view). A small, flexible, slightly conical structure (visible when the mouth is open) begins to project upwards from the centre of the lower lip (Figure 1G) and fits into a small 
A

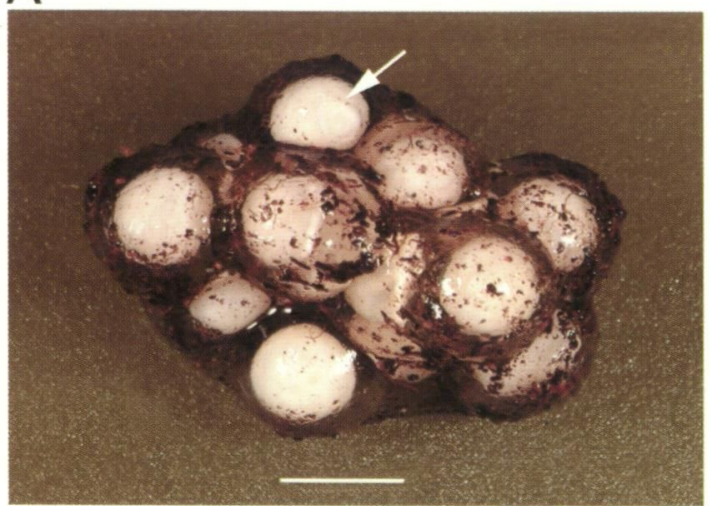

C

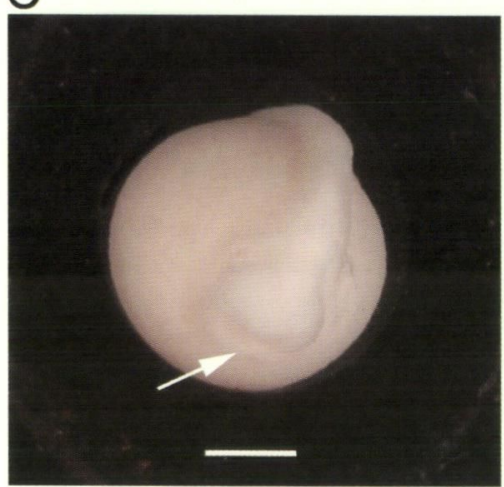

F

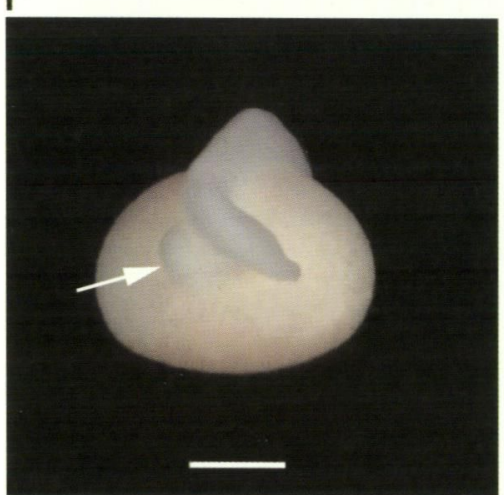

I

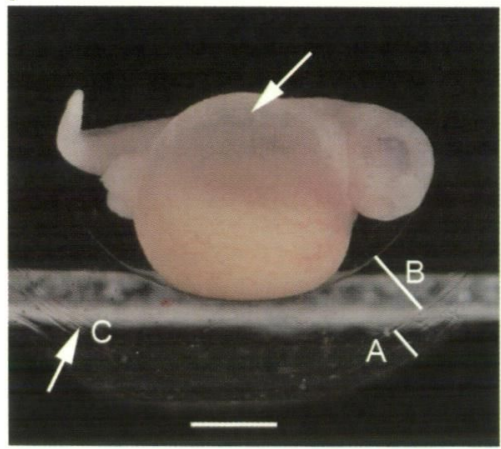

D

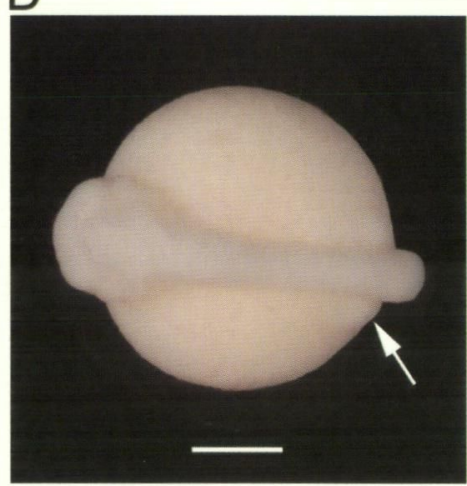

G

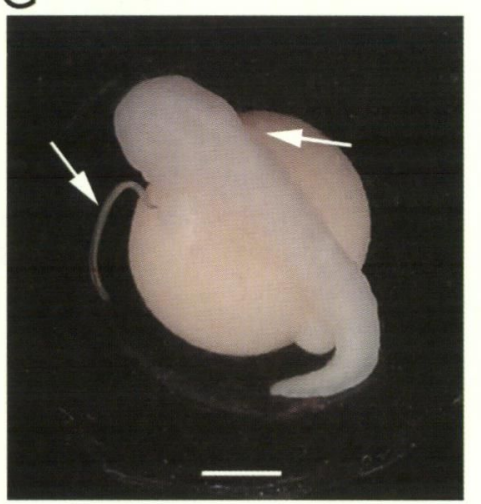

$\mathrm{J}$

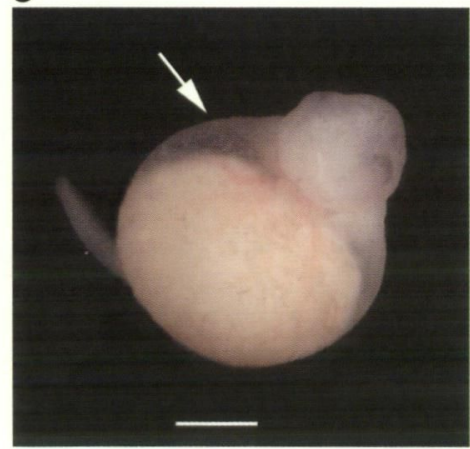

B

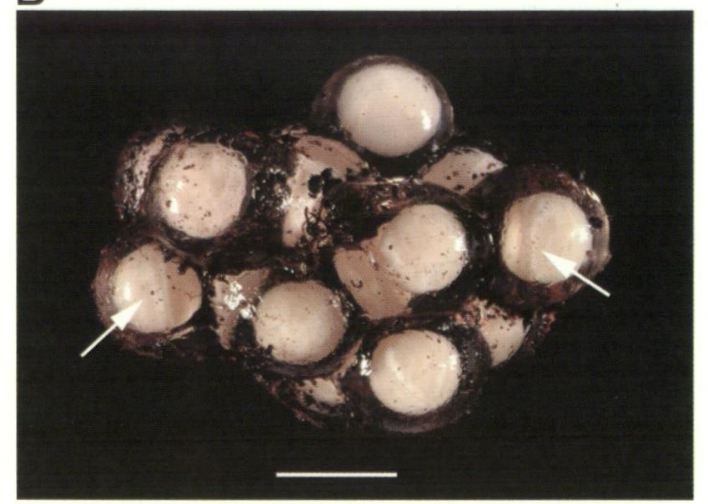

E

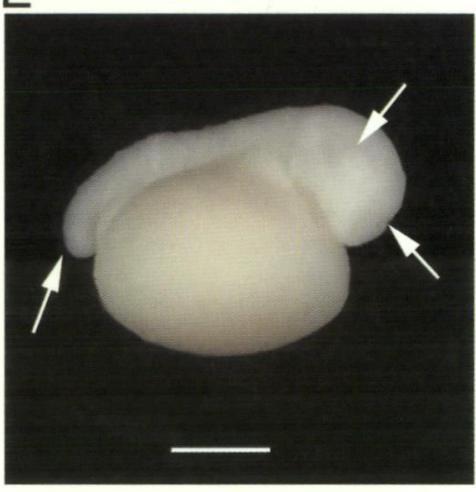

$\mathrm{H}$

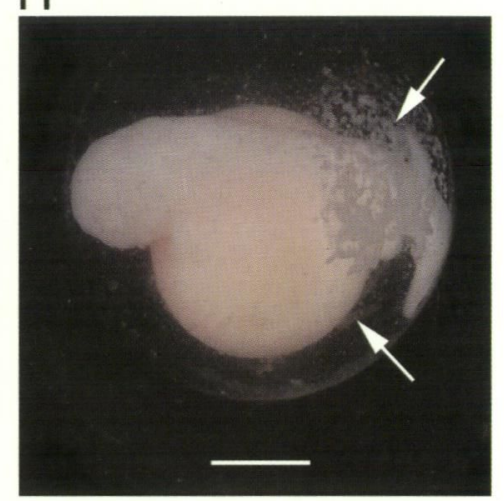

K

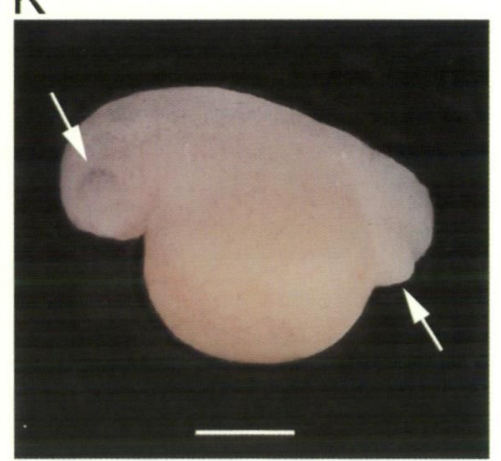

Figure 2 Stages 2-5 (Townsend and Stewart 1985) of Metacrinia nichollsi. A-B, stages 2 and 3, entire clutch, arrow = neural folds (A), neural tube (B); C, stage 3, arrow = stomodaeal depression; D-E, stage 4 during rotation, arrows $=$ hind limb bud, mouth slit, optic bulge and tail bud; F-K, stage 5 during rotation, arrows = tail bud $(F)$, predatory worm and opercular fold over forelimb bud $(G)$, worm beneath and scattered yolk caused by worm attack $(\mathrm{H})$, outer jelly layer at A, inner jelly layer at B and jelly density 'lines' at C (I), clearer area of fluid above now compressed yolk with blood vessels over yolk (J), first pigment around optic region (K). Scale bar represents $1 \mathrm{~mm}$. 
Table 1 Development of Metacrinia nichollsi. T\&S = Townsend and Stewart (1985) stages. Day = number of days since eggs were laid; Figure nos. in parenthesis. Key developmental changes are highlighted in bold, some are indicated by arrows on figures; additional features are described in text.

\begin{tabular}{|c|c|c|}
\hline T\&S & Day & Pigmentation \\
\hline 2 & $\begin{array}{c}6 \\
\text { (Fig. } 2 \mathrm{~A})\end{array}$ & $\begin{array}{l}\text { - ovum nonpigmented, } \\
\text { creamy-white }\end{array}$ \\
\hline 3 & $\begin{array}{c}7 \\
(\text { Fig.1A,B } \\
\text { 2B,C) }\end{array}$ & \\
\hline \multirow[t]{2}{*}{4} & $\begin{array}{l}8 \\
\text { (Fig. 1C,D } \\
\text { 2D) }\end{array}$ & \\
\hline & $\begin{array}{l}9-10 \\
\text { (Fig. 1C,D; } \\
\text { 2D) }\end{array}$ & $\begin{array}{l}\text { - slight translucent grey } \\
\text { shadow over mid-brain } \\
\text { region } \\
\text { - neural tube pale grey }\end{array}$ \\
\hline
\end{tabular}

Head, body, limbs, tail, behaviour

- broad neural folds

- neural tube begins to close, medial groove still visible

- head region and neural tube raised above yolk, form narrow 'dumbell' shape (2B)

- no limb buds

- small tail bud, divided by deep medial groove (1B)

- neural tube closed, indistinct myotomes

- head broadens, prominent anterior bulge on each side

- slight swelling in region of presumptive forelimb bud

- slight gill arch bulges

- tail bud more defined, projects slightly downwards just beyond yolk, medial groove begins to close

- embryo re-orients dorsally if capsule tilted

- rotation begins

- head region deeper and broader, higher above yolk, area over brain slightly arched in lateral view, myotomes just visible along neural tube

- slight hind limb bud swelling on each side of neural tube posteriorly

- swelling in presumptive forelimb bud region slightly thicker

- optic bulges slightly discernable laterally

- gill arches more distinct, 3 bulges visible, slight dermal fold develops on side of trunk, posterior to gill arch

- tail bud projects just beyond yolk, extends downwards slightly

and to right or left, groove above vent region closes

- continuous rotation ( $c$ $2 \mathrm{~F}$ ) in all specimens

- head projects slightly forward in anteroventral direction

- hind limb buds broad and round (similar to Gosner stages 26-27)

- optic regions slightly more prominent, nonpigmented

- gill arches less distinct

- tail bud further down between hind limb buds, bent to right or left

- embryos dorsiflex during first muscular response

- head lengthens, projects slightly further forward beyond yolk, snout broadly rounded in dorsal view, deep and truncate in lateral view; neural tube quite raised above yolk

- hind limb buds longer, plump and oblong (similar to Gosner stage 28)

- opercular fold extends from side of head across forelimb swelling and merges onto yolk ( $2 G)$, forelimb bud partly visible through anterior aperture $(1 \mathrm{E}, \mathrm{F})$

- no external gills develop

- tail bud lengthens down between hind limb buds and extends outwards towards vitelline membrane

- muscular response more vigorous, tail wriggles, head and trunk twist

- rotation $(2 \mathrm{~F})$ begins to slow in some

- head region projects further out beyond yolk and slightly downwards

- forelimb buds not prominent, anterior aperture in opercular fold begins to close

- iris faintly pigmented around upper edge, pupil just discernable

- tail longer, extends to vitelline membrane (2I), very narrow, tapers to pointed tip, slight dorsal and ventral fin ridges present

- strong muscular movement - tail bends from side to side right around yolk when body is twisted, tip digs hard into yolk, which indents at this pressure point 
Table 1 (cont.)

\begin{tabular}{|c|c|c|c|}
\hline $\mathrm{T} \& S$ & Day & Pigmentation & Head, body, limbs, tail, behaviour \\
\hline & $\begin{array}{c}15-16 \\
\text { (Fig. 2I-K) }\end{array}$ & $\begin{array}{l}\text { - melanophores } \\
\text { increase slightly over } \\
\text { eyes, head (except } \\
\text { brain), dorsum and yolk } \\
\text { to anterior end of tail } \\
\text { muscle (remainder of } \\
\text { tail pale translucent } \\
\text { grey) } \\
\text { - yolk compresses } \\
\text { downwards (2I,J) } \\
\text { - first vitelline blood } \\
\text { vessels }(2 \mathrm{~J})\end{array}$ & $\begin{array}{l}\text { - head region more developed, projects distinctly beyond beyond } \\
\text { body and slightly downwards, chin raised above yolk } \\
\text { - hind limb buds slightly longer, thick and oblong in shape } \\
\text { - forelimb buds fully covered, opercular fold extends from base of } \\
\text { 'chin' across bud onto yolk, anterior aperture narrows and closes } \\
\text { - eyes more defined, lateral, upper rim of iris slightly darker } \\
\text { - tail extends one-third around circumference of yolk; diminutive } \\
\text { fins, dorsal fin more defined than ventral fin } \\
\text { - rotation slows and ceases }\end{array}$ \\
\hline 6 & $\begin{array}{c}17-20 \\
\text { (Fig. } 3 \mathrm{~A}-\mathrm{D})\end{array}$ & $\begin{array}{l}\text { - head and trunk mostly } \\
\text { uniform grey } \\
\text { - extensive punctate } \\
\text { melanophores } \\
\text { dorsolaterally over } \\
\text { dorsum and yolk, } \\
\text { entire tail muscle, } \\
\text { nout, between nares } \\
\text { to upper jaw } \\
\text { - pink flush gradually } \\
\text { increases over yolk } \\
\text { (beneath } \\
\text { melanophores) }\end{array}$ & $\begin{array}{l}\text { - head lengthens downwards, narrow crevice beneath lower jaw and } \\
\text { yolk; vertebral region broader and lower } \\
\text { - ECD first become visible as white small spots (3D) } \\
\text { - hind limb buds bend around yolk, similar to Gosner stages 29-30 } \\
\text { - forelimb buds unpigmented, faintly visible beneath body wall } \\
\text { - eye appears more three-dimensional, cornea clearing, iris more } \\
\text { densely pigmented except for pale choroid fissure in middle of } \\
\text { lower half, pupil more distinct } \\
\text { - tail almost halfway around circumference of body, fins clear, } \\
\text { remain shallow } \\
\text { - tail circulation begins - single long vein along length of each fin } \\
\text { almost to tip } \\
\text { - embryos can remain laying on side for first time if egg is rolled } \\
\text { over; very active when disturbed, tail thrashes }\end{array}$ \\
\hline 7 & $\begin{array}{c}21-23 \\
\text { (Fig. 3E-I) }\end{array}$ & $\begin{array}{l}\text { - pigment denser on } \\
\text { head, snout and } \\
\text { dorsum } \\
\text { - punctate } \\
\text { melanophores } \\
\text { extend two-thirds } \\
\text { down sides of yolk } \\
\text { anteriorly, over } \\
\text { forelimb region and } \\
\text { across ventral surface } \\
\text { in narrow strip just } \\
\text { below chin } \\
\text { - few melanophores } \\
\text { on dorsal fin }\end{array}$ & $\begin{array}{l}\text { - snout short and blunt, face directed anteriorly, begins to appear } \\
\text { frog-like } \\
\text { - ECD extend laterally towards eyes ( } 3 \mathrm{E} \text { ) } \\
\text { - hind limb buds similar to Gosner stages } 31 \text { - 32, small paddle now } \\
\text { formed ( } 3 \mathrm{H} \text { ), slight knee joint constrictions } \\
\text { - forelimb bulge slightly more prominent beside head, extends to a } \\
\text { point level with anterior edge of eye (3I) } \\
\text { - heart beating clearly visible through translucent ventral wall ( } 3 \mathrm{H}) \text {; } \\
\text { internal darker areas appear to indicate some development of } \\
\text { organs (3F) } \\
\text { - thin, unpigmented ridge down middle of dorsum from behind } \\
\text { head to origin of dorsal fin ( } 3 \mathrm{G}) \\
\text { - iris black, choroid fissure narrows (3E, I) } \\
\text { - continuous blood vessel along fins right to tip of tail ( } 3 \mathrm{H}) \\
\text { - embryos very active, tail thrashes; hind limbs move individually }\end{array}$ \\
\hline 8 & $\begin{array}{c}24-27 \\
(\mathrm{Fig} .3 \mathrm{~J}-\mathrm{L} ; \\
4 \mathrm{~A}-\mathrm{C})\end{array}$ & $\begin{array}{l}\text { - pigment denser } \\
\text { over dorsum, head } \\
\text { (around brain) } \\
\text { - dark line of pigment } \\
\text { across top of nares } \\
\text { and naris to eye (3J) } \\
\text { - melanophores } \\
\text { extend to just above } \\
\text { foot on hind limbs } \\
\text { and partly over } \\
\text { venter at sides }\end{array}$ & $\begin{array}{l}\text { - head region more frog-like in proportion (3L, } 4 \mathrm{~A} \text { ) } \\
\text { - ECD extend laterally to edge of each eye (4C), merge closer } \\
\text { together medially and slightly posteriorly } \\
\text { - hind limb paddles similar to Gosner stages } 33-34 \text {, blood vessel } \\
\text { around entire edge of foot paddle ( } 4 \mathrm{~B} \text { ) } \\
\text { - shape and length of forelimb visible through body wall (3J) } \\
\text { - eye diameter increases to } 1.0 \mathrm{~mm} \text {, choroid fissure closes } \\
\text { - first distinct deep gut wall develops across yolk (3L), horse-shoe } \\
\text { shape laterally (3K) } \\
\text { - tail at full development, extends about midway around } \\
\text { circumference of body; circulation much increased, fine network } \\
\text { of secondary blood vessels across each fin (4B) } \\
\text { - embryos very active; mouth opens and closes frequently }\end{array}$ \\
\hline
\end{tabular}


Table 1 (cont.)

\begin{tabular}{|c|c|c|}
\hline T\&S & Day & Pigmentation \\
\hline 9 & $\begin{array}{c}28-32 \\
\text { (Fig. 4D-F) }\end{array}$ & $\begin{array}{l}\text { - melanophores } \\
\text { denser over head } \\
\text { (4D), around nares } \\
\text { and most of upper } \\
\text { lip; extend over hind } \\
\text { limbs and partly } \\
\text { onto feet, ventrally } \\
\text { across base of yolk } \\
\text { and over throat } \\
\text { - first gold flecks on iris } \\
\text { - fine gold iridophores } \\
\text { just visible from head } \\
\text { to middorsal region }\end{array}$ \\
\hline
\end{tabular}

$10 \quad 33-36$

(Fig. 1G-I: 4G-I)
- pigment denser over limbs and feet, snout and tail muscle, sides of abdomen

- medial one-third of ventral surface remains unpigmented

- iridophore flecks across tops of eyes, between nares, over snout, head and dorsum

- copper-gold flecks increase around pupil

- ECD mostly obscured by pigment

- iridophores increase over iris (4K), snout, head and vertebral region to base of hind limbs

- few flecks visible on tail muscle

- forelimbs pigmented

- melanophore coverage complete over dorsum and limbs

- iridophore flecks increase over iris, head, body and tail

- dorsal surface of limbs and vertebral region flushed with pink
Head, body, limbs, tail, behaviour

- hind limbs longer, similar to Gosner stages 35 (4E)

- forelimbs gradually begin to elevate at elbow beneath operculum, extend around each side of head to just under chin

- head region longer; vertebral region flatter except for slight 'hump' over shoulder region and narrow middorsal ridge (4D)

- ECD extend in a line around anterior perimeter of mid-brain region

- iris black, pupil clear grey, first gold flecks just visible on iris around pupil (4E)

- tail muscle myotomes visible, fins reduce slightly, main longitudinal blood vessel present, smaller blood vessels gone

- heart beats at 44 beats per minute at $17^{\circ} \mathrm{C}$

- mouth opens frequently, muscles twitch at sides of jaws, lower jaw juts forward and back, body twists, tail twitches, feet clasp together $(4 \mathrm{~F}$, of $4 \mathrm{H})$ and move apart

- hind limbs longer, knee joints distinct and bent, toes similar to stages 36-37 Gosner, almost $1 / 3$ length at hatching

- forelimbs extend beneath chin to each side of heart region (4I), fingers visible beneath body wall, elbow bulges more prominent (1G)

- ECD form thin white outline around entire perimeter of midbrain region, merged dorsally in some (4G)

- raised area over brain more prominent; middorsal ridge still visible

- eye diameter $1.1 \mathrm{~mm}$, pupil bluish to black, surrounded by more extensive iridophores in some

- tail still moves abruptly from side to side across body, body ventriflexes - base of body and tail moves inwards and upwards towards head

- feet clasp together $(4 \mathrm{H})$ and move apart, often slowly, movements more subtle and controlled

- forelimbs emerge (4J) one at a time (either left or right elbow pushes through first), fingers visible but not separated until a day after limb emerges $(4 \mathrm{~L})$

- hind limbs longer, toes similar to Gosner stages 37-38

- ECD merge dorsally, extend right around brain region (4K)

- eye diameter increases slightly - diameter $1.2 \mathrm{~mm}$

- forelimbs and hind limbs are moved independently and simultaneously, hands thrust downwards $(4 \mathrm{~K})$; toes twitch, limbs move together and apart; mouth quite frequently held partly open (4L), tongue moves; body twists quickly to one side

- fingers all clearly distinguishable on forearms, blood vessels visible down either side of longest finger

- legs lengthen, similar to Gosner stages 39-40, extend about one third around circumference of yolk, subarticular tubercles visible along underside of toes

- ECD well obscured by pigment, reduced slightly dorsally, still present around chondrocranium

- eyes larger, embryos turn away from light source

- tail same length, main blood vessels still present

- embryos actively move around capsule; mouth opened widely and shut again, tongue moves forward or back in mouth; hands and feet move frequently limbs full length and held in sitting position of adult 
Table 1 (cont.)

\begin{tabular}{|c|c|c|c|}
\hline T\&S & Day & Pigmentation & Head, body, limbs, tail, behaviour \\
\hline 13 & $\begin{array}{c}50-53 \\
\text { (Fig. } 5 \mathrm{~B}-\mathrm{C} \text { ) }\end{array}$ & $\begin{array}{l}\text { - iridophores extensive } \\
\text { over head, entire } \\
\text { dorsum, limbs (above } \\
\text { and beneath) and tail } \\
\text { muscle } \\
\text { - eyelids outlined with } \\
\text { pale gold (5B) }\end{array}$ & $\begin{array}{l}\text { - head broad, distinctly frog-like } \\
\text { - hind limbs more developed, similar to Gosner stage } 41 \\
\text { - eyelids form (5B), eyes lateral and prominent, diameter about } 1.2 \\
\text { mm, iridophores form broad gold ring around pupil, cornea } \\
\text { protrudes beyond level of body wall } \\
\text { - tail reduction begins, fins and muscle shrink slightly } \\
\text { - ECD still partly visible } \\
\text { - throat undulates in regular adult-like breathing action (observed } \\
\text { while in water, but may continue out of water); arms and legs more } \\
\text { flexible, move more freely }\end{array}$ \\
\hline 14 & $\begin{array}{c}54-61 \\
\text { (Fig. 5D) }\end{array}$ & $\begin{array}{l}\text { - pigmentation patterns } \\
\text { now denser and more } \\
\text { defined } \\
\text { - gold iridophores more } \\
\text { concentrated on face } \\
\text { and eyelids } \\
\text { - reddish-brown } \\
\text { apparent on head } \\
\text { - narrow, pale } \\
\text { middorsal stripe to } \\
\text { base of urostyle }\end{array}$ & $\begin{array}{l}\text { - limbs fully developed, similar to Gosner stages } 42-45 \\
\text { - head very close to outer wall of unhydrated capsule } \\
\text { - eyes like adult in shape, diameter } 1.4 \mathrm{~mm} \text {, eyelid more defined } \\
\text { - tail gradually reduces to small remnant (5D) } \\
\text { - ECD reduced, mostly obscured by pigment } \\
\text { - extensive movement within capsule, body twists right around to } \\
\text { face opposite direction in capsule, leg and arm movement frequent, } \\
\text { limbs frequently pressed or kicked against capsule, hands and } \\
\text { feet used to assist turning around within capsule }\end{array}$ \\
\hline 15 & $\begin{array}{c}62-74 \\
\text { (Fig. 5E-G) }\end{array}$ & $\begin{array}{l}\text { - urostylar region } \\
\text { darkens in one } \\
\text { specimen } \\
\text { - adult pigment } \\
\text { becoming evident }\end{array}$ & $\begin{array}{l}\text { - tail stub visible ( } 5 \mathrm{~F} \text { ), then completely resorbed (Gosner } \\
\text { stages } 4546 \text { ) } \\
\text { - hind limbs stretched forwards along full length of body to } \\
\text { beyond head, then kicked backwards and downwards suddenly } \\
\text { towards outer jelly layer ( } 5 \mathrm{E} \text { ) } \\
\text { - embryos assisted to hatch six and nine days after tail resorption } \\
\text { when yolk was diminished, movement and attempts to hatch } \\
\text { greatly reduced } \\
\text { - fluid oozes from vitelline membrane during breaking of egg } \\
\text { capsule, embryo begins to walk after hatching }\end{array}$ \\
\hline
\end{tabular}

corresponding notch centered on the inside of the upper lip. By stage 10, the mouth slit widens and the chin is well differentiated. By stage 13, the mouth opening extends to a point in line with twothirds across the length of the eye and appears fully formed. The conical projection becomes more defined during stages 12-15 (Figure 5 C, D), and the inner margin of the notch deepens posteriorly into a distinct depression by stage 15 , into which the conical projection fits when the mouth is closed. These structures remain in the adult.

\section{Gut}

The first sign of gut development occurs at late stage 5 when the yolk compresses downwards creating a translucent, apparently fluid-filled gap between the vertebral region and the yolk (Figure $2 \mathrm{I}, \mathrm{J})$. This translucent area appears denser and less translucent during stage 6. There is a small amount of loose yolk material and fine yolk granules floating within the vitelline fluid from stage 5 , most of which forms a clump in subsequent stages $(4 \mathrm{~F})$. The first vitelline blood vessels are visible during stage 5 ventrally over the gut (Figure $2 \mathrm{I}-\mathrm{K}$ ) and these become more extensive and distinct ventrally and laterally as the body broadens during stage 6 (Figure $3 \mathrm{C}$ ). By stage 7 , some internal darker areas are visible above the yolk, possibly indicating initial formation of internal organs. During stage 8 , the initial indication of gut wall development is a slight shadow in the left side of the yolk. A thick inverted U-shape gut loop forms on the left side (Figure $3 \mathrm{~K}$ ), and the first distinct gut wall extends across the yolk ventrally (Figure 3L). During stage 9, the diameter across the abdomen diminishes slightly. The fine, loose yolk granules floating within the vitelline fluid were observed to circulate slowly until they passed in front of the snout (Figure 4E), where they were suddenly propelled rapidly downwards over the belly. During stage 10, two ventral gut loops are visible across the abdomen (Figure $4 \mathrm{I}$ ), and during stage 11 the sides develop two inverted U-shaped loops, one inside the other (Figure $4 \mathrm{~K}$ ). Three loops extend across the abdomen by stages 11-12 (Figure 4J). At stage 13, the gut loops are narrower and during stages 14-15, the yolk begins to diminish further. 
A

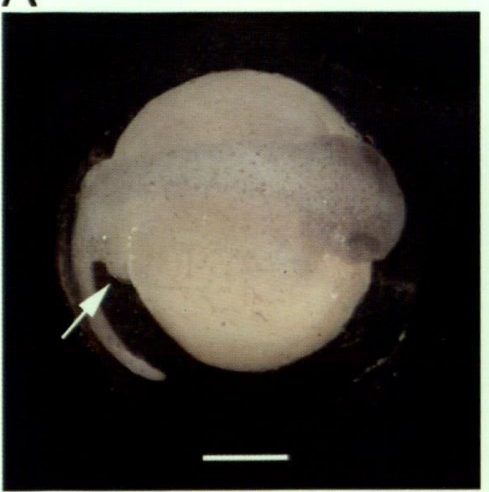

D

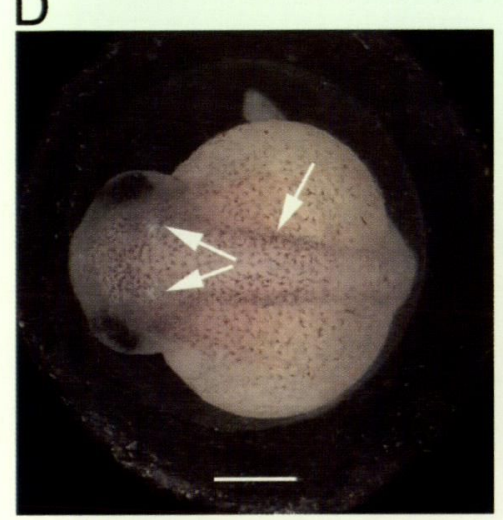

G

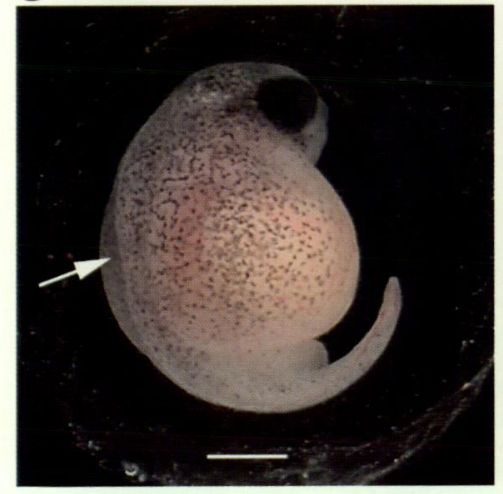

J

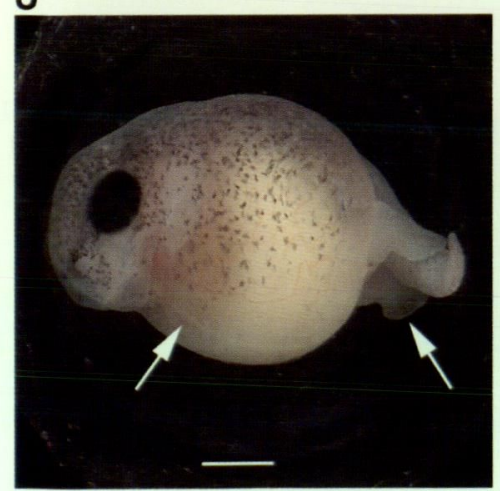

B

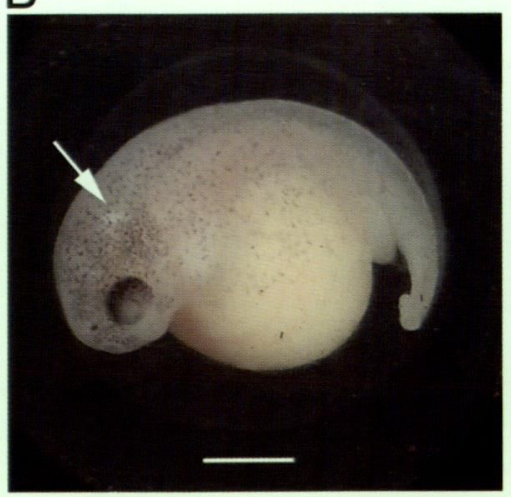

E

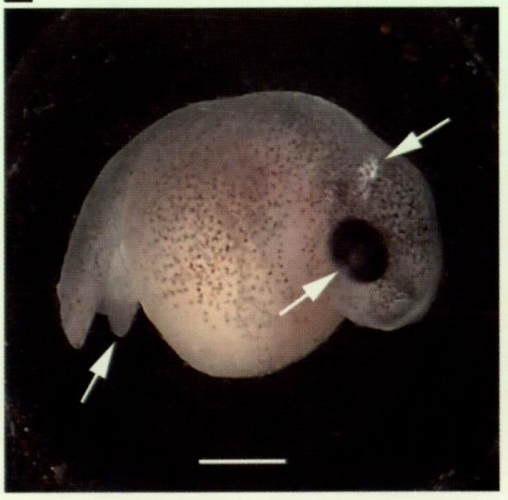

$\mathrm{H}$

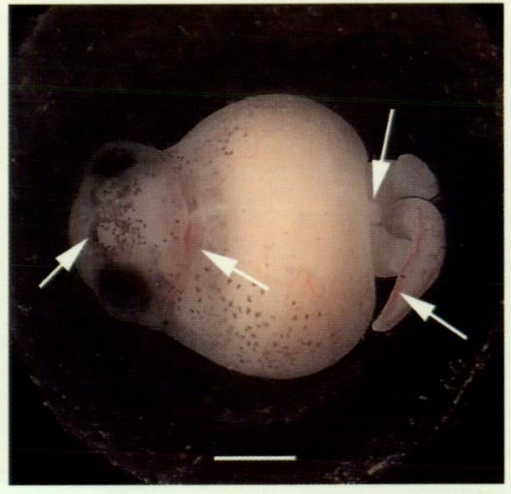

K

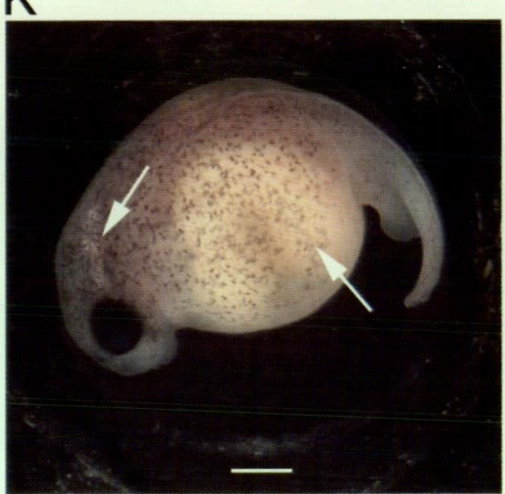

C

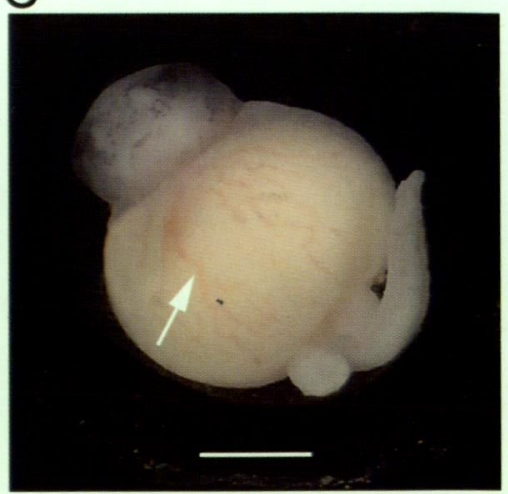

F

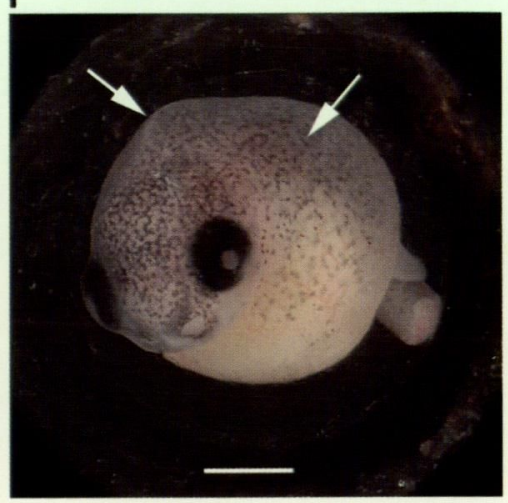

I

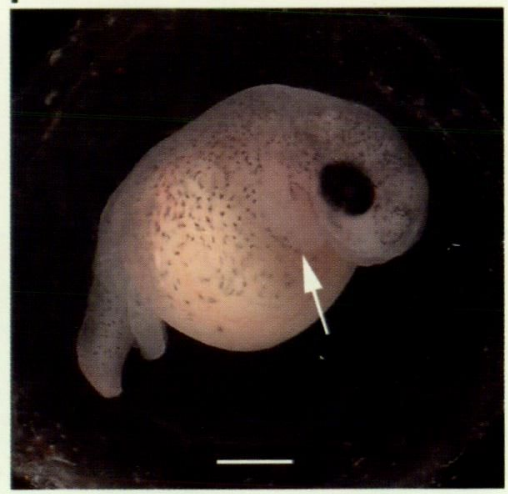

L

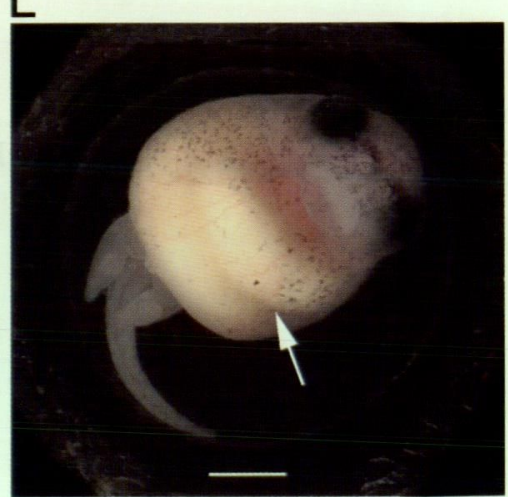

Figure 3 Stages 6, 7 and 8 (Townsend and Stewart 1985) of Metacrinia nichollsi. A-D, stage 6, arrows = hind limb bud, first ECD and vitelline blood vessels (A-C), ECD and broader vertebral ridge (D); E-I, stage 7, arrows = hind limb bud, ECD, slight choroid fissure in eye (E), narrow middorsal ridge, increased melanophore pigment $(F, G)$, pigment around nares, heart, extended tail and vent tube opening $(\mathrm{H})$ forelimb bud beneath operculum; J-L, stage 8 , arrows $=$ midventral pleat in body wall $(c f \mathrm{H})$ and foot paddle $(\mathrm{J}), \mathrm{ECD}$ and $\mathrm{U}$ shaped gut loop (K), first distinct gut wall (L). Scale bar represents $1 \mathrm{~mm}$. 


\section{Endolymphatic calcium deposits (ECD)}

The ECD are first visible at stage 6 as a pair of small white deposits posterior to the mid-brain (one on each side; Figure 3D), and these soon become small rounded patches. By stage 7 , they extend laterally towards the eyes (Figure $3 \mathrm{E}$ ) and are bright white and broader. At stage 8 , they merge closer dorsally, extend slightly posteriorly down the vertebral region and laterally to the edge of each eye (Figure 4C). During stage 9, they merge dorsally in most embryos (Figure 4D), extend further posteriorly and continue in a line around the perimeter of the anterior half of the brain region. By stage 10 , they form a thin white outline around the entire perimeter of the brain region (Figure $4 \mathrm{~K}$ ). By stage 12 , they are well obscured by pigment and reduced slightly dorsally, but still present around the perimeter of the brain. During stages 13-15, they are mostly obscured by pigment and further reduced.

\section{Body Wall}

The body wall appears to develop during stage 5 and has a whitish tinge, but it gradually becomes increasingly translucent during late stage 5 to stage 12. During stage 5 , fine melanophores first appear dorsally within the body wall over the head and vertebral region (Figure $2 \mathrm{~K}$ ). From early stage 7 to stage 11 , a narrow, unpigmented pleat or ridge extends down the middle of the vertebral region from the back of the head to the origin of the dorsal fin (Figure 3F, G; Figure 4D) and begins to flatten during stage 11 . During stage 8 , a thin, longitudinal 'pleat' develops in the body wall down the centre of the abdomen (Figure $3 \mathrm{H}, \mathrm{J}$ ) and this flattens during stage 9, probably expanding the body wall surface. During stages 13-14 the body wall becomes slightly thicker and looser, and more translucent and flexible folds form across the belly and sides (Figure 5D); a depression in the body wall is easily made when the embryo presses a hand into the body.

\section{Nares}

The narial pits are first visible at early stage 5, when they are directed anteriorly and partly perforated and slightly pigmented around the edge by three days later. During stages 6-7 they are fully perforated with a slight rim, ringed with melanophores (Figure $3 \mathrm{H}$ ) and open anterolaterally. The diameter of the opening is $0.2 \mathrm{~mm}$ by stages 8 and 9 and they are progressively more pigmented around the rim, especially dorsally (Figure 4A). By stage 10 they appear fully formed and open anterolaterally (Figure 1G).

\section{Vent}

The vent begins as a shallow, perforated indentation in the yolk beneath the tail bud during stages 3-4 (Figure 1B). By late stage 5, it is more defined with a narrow rim around the opening that thickens and appears divided posteriorly during stage 6 then continuous by stage 7 (Figure $3 \mathrm{H}$ ). The opening slightly elongates to just beyond the posterior edge of the thighs during stages 9 (Figure $4 \mathrm{E}$ ) and 10 and forms into the position of the adult during stages 14-15.

\section{Size during development}

Dimensions of live embryos from the clutch raised in the laboratory are presented in Appendix 1 (morphometric measurements of an anaesthetised embryo at stage 10) and Appendix 2 (live embryos in capsules from stages 2-15). The first live embryos at stages 2 and 3 were measured out of water and subject to slight distortion through the jelly, so measurements are slightly larger than those of embryos a day later at stage 4 . The minimum mean diameter of 11 embryos at early stage 4, measured across the width of the yolk while immersed in water was $2.9 \mathrm{~mm}$ (range 2.9-3.1). During stage 3, the head region projects very slightly beyond the yolk. In stage 4 , the head and tail bud broaden more and project further beyond the yolk (Figures 1D; $2 D, E)$. From stage 4 to early stage 9 , the total length of the embryo was measured in dorsal view from the tip of the snout to the posterior edge of the tail bud or curved tail, and width was measured across the middle of the yolk. During late stage 9 to stage 11 , when the yolk is slightly reduced, only the length is given. Both snout-vent lengths (measured in ventral view) and total length including the tail prior to full resorption (measured in dorsal view) are provided for the two remaining specimens in stages 12-15. Two anaesthetised hatchlings at stage 15 were measured in dorsal view.

\section{Observations on attack by predatory worm}

During stage 5 on day 11, a thin, translucent nematode worm (1.7 $\mathrm{mm}$ in length) was observed within the jelly capsule encircling the outside of the vitelline membrane of one embryo (Figure 2G). By day 13 , the worm had passed through the vitelline membrane and began attacking the embryo at the base of the body, behind which numerous yolk granules became scattered around the inside of the vitelline membrane (Figure $2 \mathrm{H}$ ). The embryo was preserved with the worm in situ. The worm has been identified as a member of the family Dorylaimidae and probably of the genus Dorylaimus, a worm which is found in soil and normally attacks plant matter (D. Spratt and M. Hodda, pers. comm.).

\section{Hatchlings}

Specimen 1: six days after tail resorption (day 70 ). Snout short and truncate in lateral view; small clear, 
A

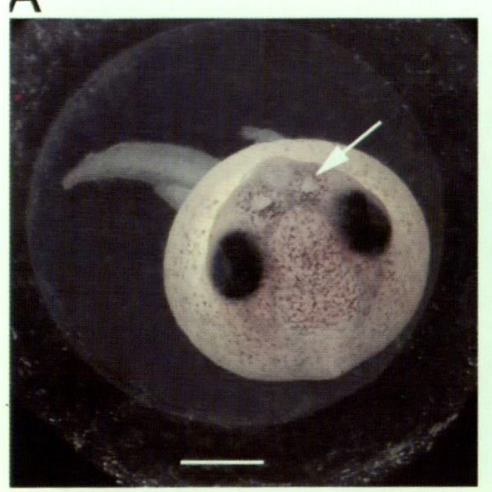

D

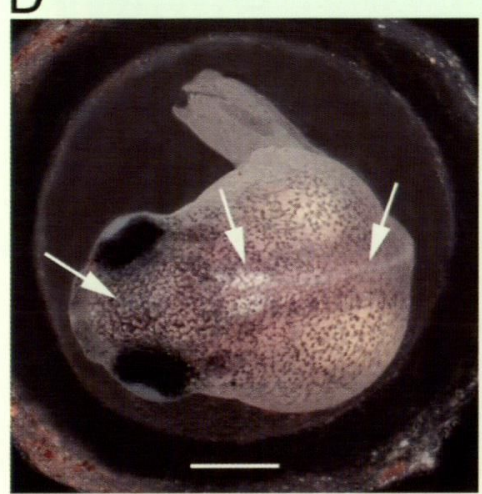

G

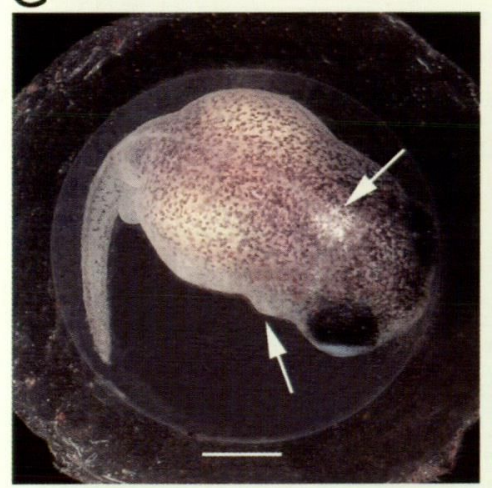

J

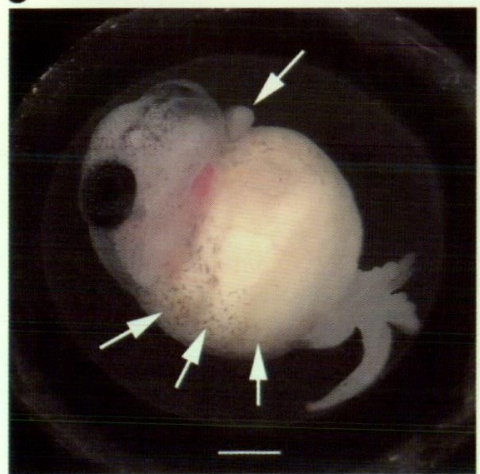

B

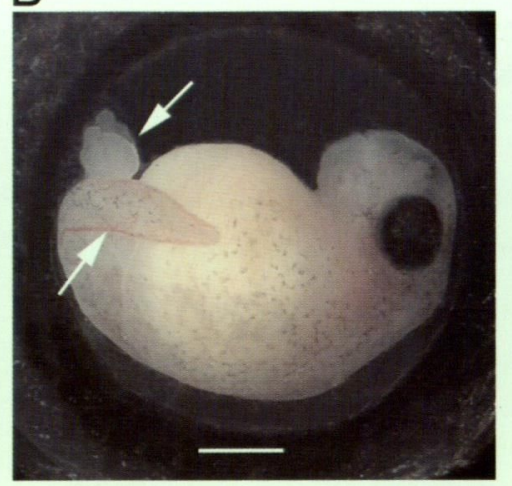

E

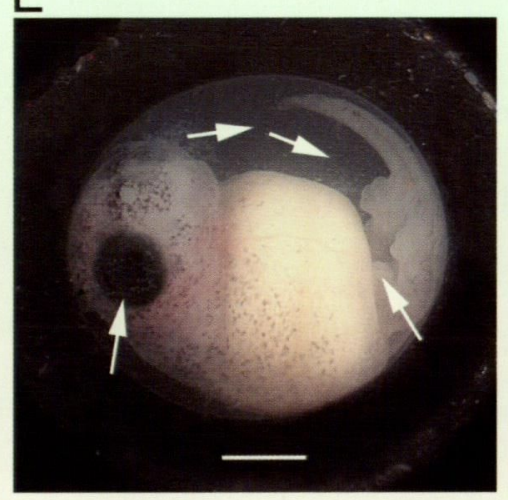

$\mathrm{H}$

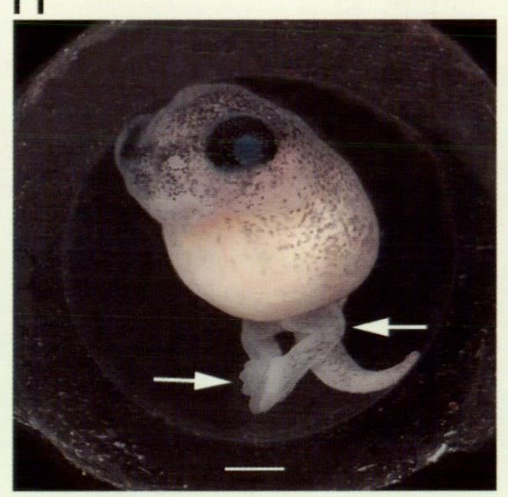

K

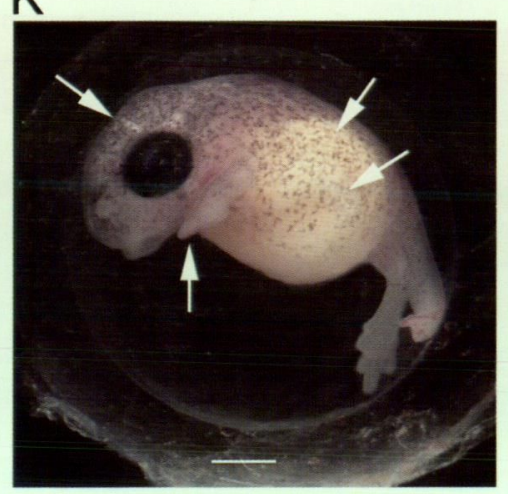

C

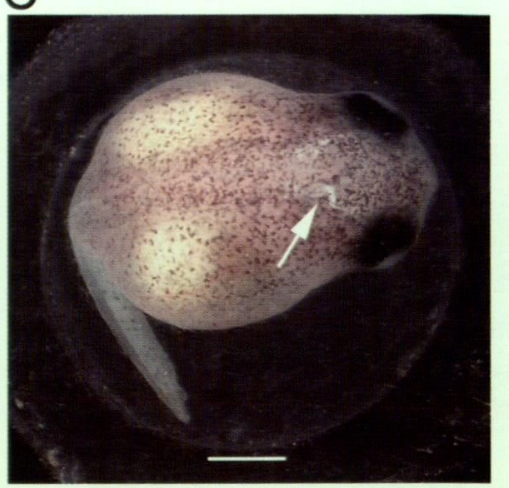

F

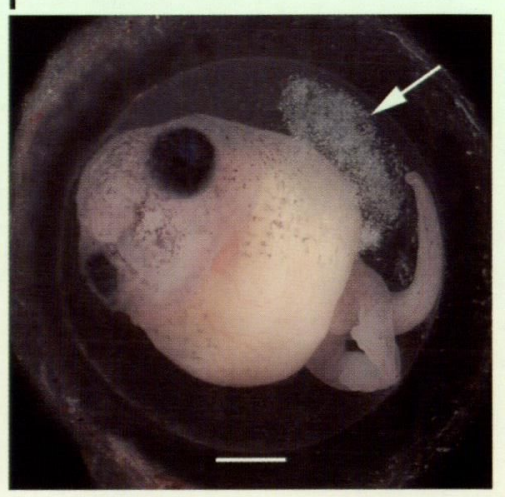

I

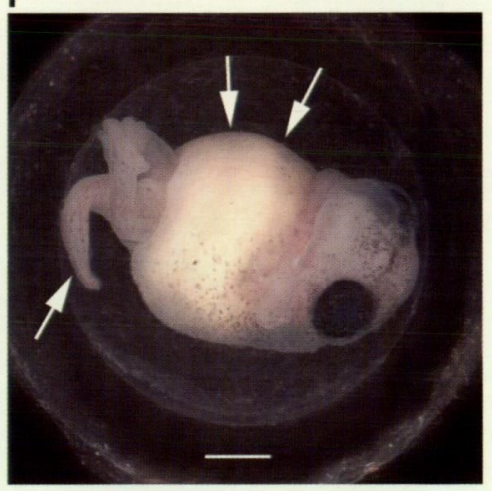

L

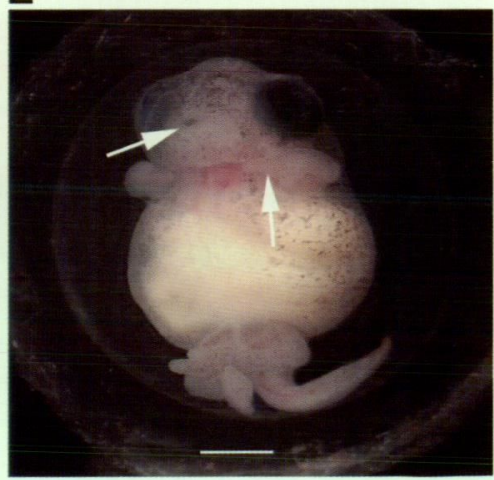

Figure 4 Stages 8-11 (Townsend and Stewart 1985) of Metacrinia nichollsi. A-C, stage 8, arrows = narial opening, foot paddle with blood vessels, tail fin blood vessels and ECD; D-F, = stage 9, arrows = dense pigment on head, ECD and narrow middorsal ridge (D), first gold flecks begin on iris, direction of fast moving yolk granules in vitelline fluid after passing over snout, vent (E), clump of yolk granules (F); G-I, stage 10, arrows = ECD and forelimb bulge (G), feet clasping and knee joints $(\mathrm{H})$, two gut loops and tail thrashing sideways (I); J-L, stage 11 , arrows = emerging left forearm and 3 gut loops $(\mathrm{J})$, ECD, emerged hand and two U-shaped gut loops $(\mathrm{K})$, open mouth and one of two emerged forearms (L). Scale bar represents $1 \mathrm{~mm}$. 

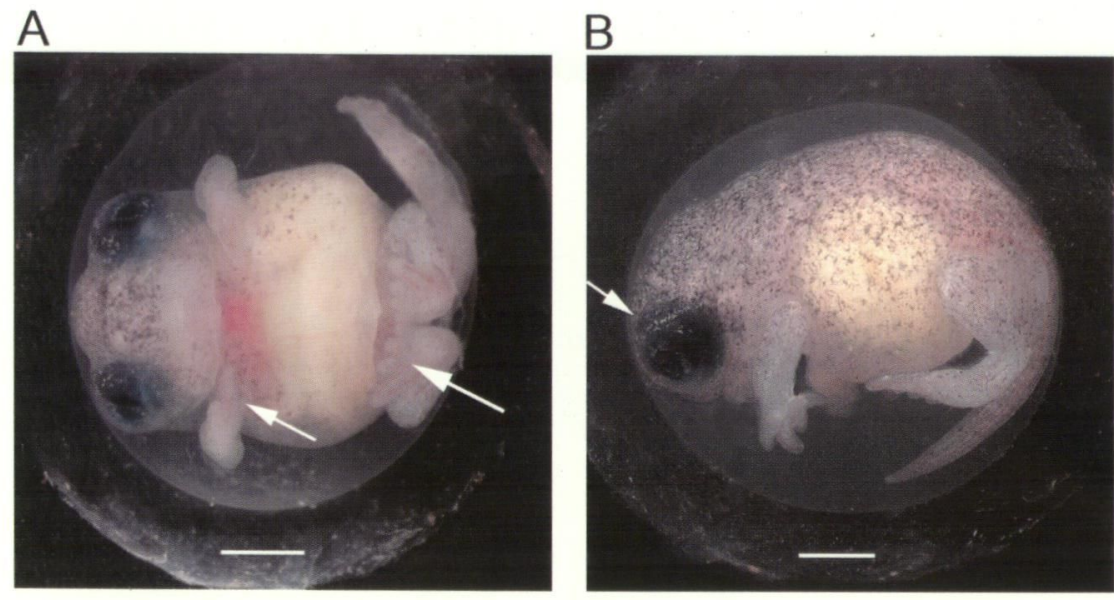

C

D

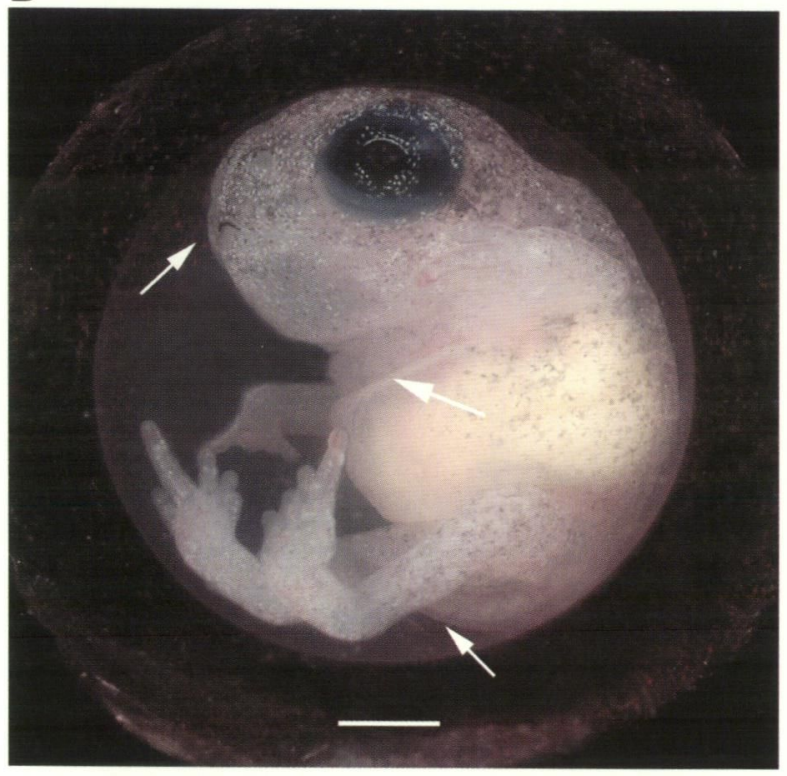

$\mathrm{F}$

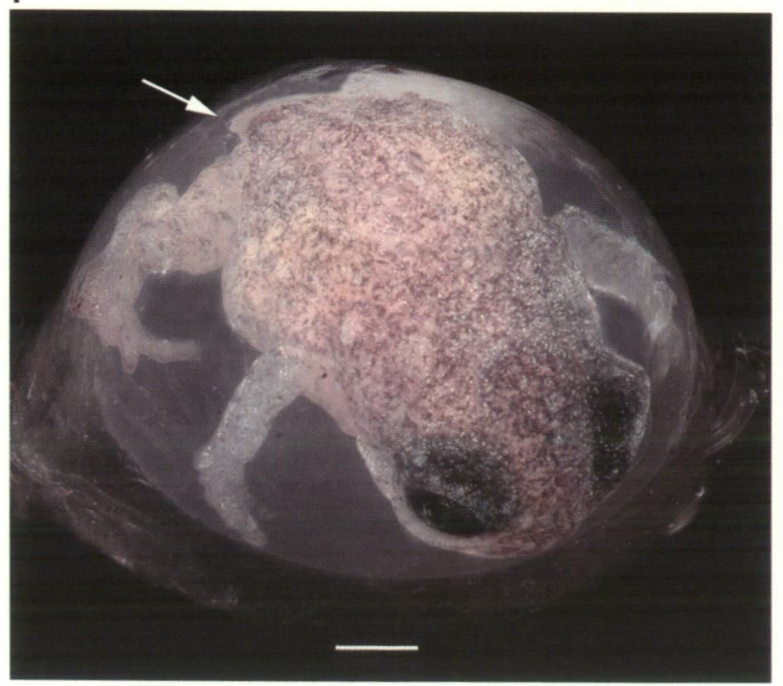

E

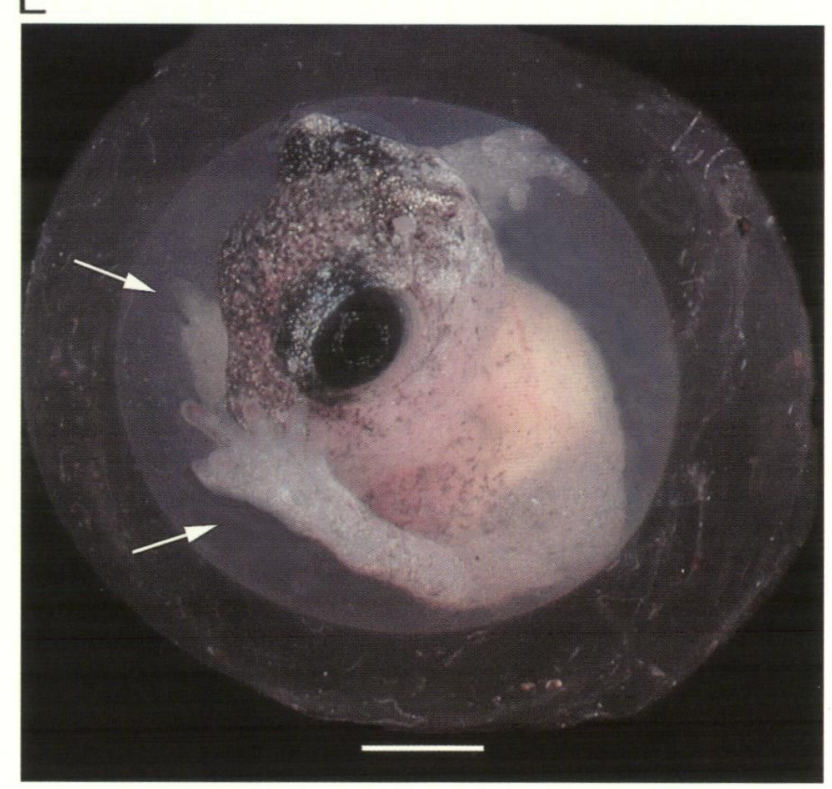

$\mathrm{G}$

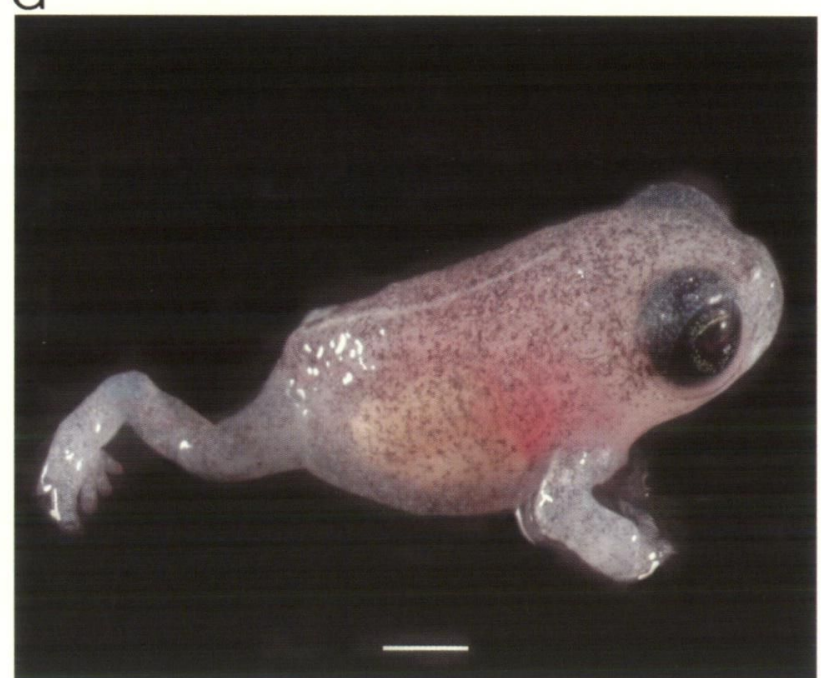

Figure 5 Stages 12-15 (Townsend and Stewart 1985) of Metacrinia nichollsi. A, stage 12, arrows = hand and foot (blood vessels); B-C, = stage 13, arrows = eyelid and conical projection on lower lip; D-F, = stage 14, arrows = open mouth with conical projection on lower lip, ventral fold in body wall and tail stub (D), hind limbs prior to downward thrust of legs as embryo attempts to hatch, tail stub (E), tail stub (F); G, stage 15, just hatched and walking. Scale bar represents $1 \mathrm{~mm}$. 
slightly conical projection on inside centre of lower lip (Figure 5C, D) and corresponding shallow notch in upper lip; mouth opening extends laterally to a point level with about three-quarters across diameter of eye; venter translucent, heart, lungs, liver and stomach visible; gut not yet transformed into adult intestines; eye diameter $1.1 \mathrm{~mm}$, gold iridophores concentrated above and below pupil, nictitating membrane present; no tympanum yet visible (visible in adult), traces of gold above this area.

Dorsum and limbs densely pigmented; thin, pale gold middorsal stripe, dense pale gold defines edges of eyelids, coppery-gold stripe vertically between nostrils (Figure 5D); ridge of gold-tipped tubercles at each end of mouth, gold around edge of lower lip and over throat, upper lip has dark vertical bars alternating with silvery iridophores; fine gold iridophores among melanophores all over dorsum, sides of body and limbs, including fingers and toes; gold over vent region.

Specimen 2: nine days after tail resorption (day 73). Specimen not active during assisted hatching, despite stimulation, and yolk much reduced. Began to walk a few minutes after release from jelly capsule (Figure 5G).

Pigment differed from specimen 1 as follows: dorsum not as dark, snout and lips more uniform and much less defined into concentrated areas or patterns; gold iridophores mainly above and below pupil, not widespread over iris; only a few goldtipped tubercles over edge of eyelid. Specimen 2 survived for two days after release, but did not feed and was then preserved. SVL of two live hatchlings: 6.4 and $6.3 \mathrm{~mm}$.

\section{DISCUSSION}

\section{Comparisons between the three Australian myobatrachid genera}

The known sites of egg deposition of Metacrinia (in dry sand beneath leaf litter or in a hollow under a $\log$ or stone) differ from those of Myobatrachus and Arenophryne, both of which deposit eggs deep within sandy subterranean sites (Roberts 1981, 1984). From documented observations here of Metacrinia clutches found with one (a male) or two frogs (sex not determined) in attendance, it seems likely that at least one frog (most probably the male) remains with the eggs during all or much of development. The total number of eggs in the three known clutches ranged from 12-25 or 30 (mean 17 or 19), and this is similar to the mean of 25 eggs for five Myobatrachus clutches but much larger than the mean of 7 eggs for five Arenophryne clutches (Anstis et al. 2007).

The development of $M$. nichollsi is quite similar to that of $A$. rotunda (" $A$." below) and $M$. gouldii
("M." below) (Anstis et al. 2007). Metacrinia shares the following characteristics with these two related genera:

- large, nonpigmented ova

- no external gills, adhesive glands or spiracle

- early limb bud development prior to any visible optic pigmentation

- development of mouth with no oral structures of a tadpole

- the small, slightly conical ridge in the centre of the lower lip and corresponding notch in the upper lip of unknown function that develop from stage 9.

Some differences in the timing of development were noted in the following ways:

- the emergence of the forelimbs (stage 11 for Metacrinia; stage 7 for $A$. and stage 9 for $M$.).

- the eyes develop pigment gradually from stage 5 and increase noticeably in diameter (from stage 8 in Metacrinia; stages 6-8, $A$. and $M$.)

- the neural tube is initially raised above the large yolk, then gradually flattens and broadens (from about stage 6 onwards in Metacrinia; stages 4-5, A. and $M$.)

- the gut gradually develops from initial divisions in the yolk (stage 8 in Metacrinia; stage $6, A$. and $M$.), into a thick intestinal coil (stages 9 and 10 Metacrinia; stage $9, A$. and $M$.)

- frog-like features of the head develop from as early as stage 8 (Metacrinia; at least stage 9, $A$ and $M$.)

- a narrow, pleat or ridge forms down the middle of the dorsum as vertebrae begin to develop in Metacrinia (Figure 3E-G), which was not observed in preserved $A$. and $M$.

More live material of all three genera needs to be studied to determine whether the above differences are consistent.

Both $A$. rotunda and Metacrinia have a shorter tail with very low fins and much narrower tail tip than $M$. gouldii, which has a much longer tail, broad well-vascularised fins and a broadly rounded tip. The much reduced surface area of the fins of $A$. rotunda and Metacrinia compared to the very broad fins of $M$. gouldii, suggests the tail has a reduced vascular function in the former genera. Full vascular development is only present in the narrow fins of Metacrinia during stage 8 , and the network of smaller blood vessels is gone by stage 9 , when only one main longitudinal vessel remains around the edge of the fins.

\section{Comparisons with Eleutherodactylus coqui}

Differences between E. coqui and Myobatrachus and Arenophryne are listed in Anstis et al. (2007) and including Metacrinia, the three myobatrachids differ from $E$. coqui in the following ways: 
- they do not develop an egg tooth

the initial development of the forelimbs is internal prior to stages 7,10 or 11 (external from first appearance at stage 4 in E. coqui)

- the tail bud begins to develop slightly earlier from stage 3 in Metacrinia (stage 4, E. coqui)

the tail is more advanced in development by stage 5 (Myobatrachus), and fins are much narrower in Arenophryne and Metacrinia

there are no external gills

the development of melanophores over the dorsum is within the body wall, and does not become a 'disc flanking the trunk' that has a 'leading edge', as described for E. coqui (Townsend and Stewart 1985).

Apart from the differences noted above, the southwestern Australian genera have generally similar developmental life histories to $E$. coqui, but without observations of live material of Myobatrachus and Arenophryne, it has not been possible to adequately compare aspects of gut, mouth and eye development, vitelline circulation and behaviour with those described for Metacrinia, and for E. coqui.

\section{General observations}

The observation by Driscoll (1998) of some males calling from $50 \mathrm{~cm}$ above the ground is highly unusual calling behaviour for a myobatrachid ground frog and is similar to the elevated calling positions of direct developing microhylids in the tropics (Hoskin 2004). The further observation by Driscoll of a female calling in a site typical of that used by a male, has not been reported for other Australian frogs and warrants further investigation.

The jelly layer of Metacrinia eggs swells when hydrated in water and gradually shrinks again during normal periods of maintenance on moist filter paper. When moisture was added to the paper less frequently than twice a day, the outer surface of the layer became slightly drier and tougher, similar to the dry outer coating described for field collected eggs of $A$. rotunda and $M$. gouldii (Roberts 1981, 1984; Anstis et al. 2007).

The brief daily periods of immersion of embryos in water during much of development for purposes of photography and study may have contributed to the development of possible cedema in two embryos at stage 10, as they would not typically be exposed to periods of inundation until closer to hatching in egg deposition sites in the field. It is not known whether the presence of yolk granules in the vitelline fluid from stage 5 is normal, or whether it was a result of culture methods, but it may have been a stress-related reaction to the daily immersions in water. The observation of the freefloating yolk granules which were suddenly propelled downwards along the throat and belly when they passed in front of the snout, indicates the flow pattern that would be generated by epidermal cilia (R. Altig pers. comm.).

The mean diameter (width) of the preserved embryos at stage 3 from WAM R8543/44 was 2.5 $\mathrm{mm}$, but some shrinkage would have occurred in ethanol. The diameter of freshly laid embryos is likely to be about $2.9 \mathrm{~mm}$ (Appendix 2), taken from the smaller width dimension of embryos in stage 4 , as these embryos were measured in water, while the slightly larger dimensions given for stages 2 and 3 were of embryos measured out of water (measurements slightly distorted). This is noticeably smaller than the $5.0 \mathrm{~mm}$ diameter for $A$. rotunda embryos (stages 1-4) and $5.6 \mathrm{~mm}$ (stage 5) for $M$. gouldii embryos (Anstis et al. 2007), but adult females of Metacrinia are also smaller $(22-24 \mathrm{~mm})$ compared with 28-33 mm for female Arenophryne and 44-50 $\mathrm{mm}$ for female Myobatrachus (Tyler et al. 2000). From the small amount of embryonic material available, indications are that all three genera approximately double their length at least, from stage 1 to hatching at stage $15(2.9-6.3 \mathrm{~mm}$, Metacrinia, this paper); $5.0-10.2 \mathrm{~mm}$ A. rotunda, and about $5.5-10.1 \mathrm{~mm}$ (M. gouldii; Anstis et al. 2007). The embryo at stage 10 removed from the jelly and measured with tail outstretched (Appendix 1) has a tail/body ratio of 0.57 , and the tail is much shorter than that of typical Australian exotrophic tadpoles, most of which have a tail that is about two-thirds the length of the body (Anstis, unpublished data). The body is slightly wider than deep and the tail muscle is narrow and slim (ratio of tail muscle depth to body depth 0.2).

The attack by the nematode worm (Dorylaimus $\mathrm{sp}$.) is of interest, as this worm is previously only known to be free-living in soil, or parasitic on plant matter (D. Spratt pers. comm.).

\section{Embryonic life span and hatching}

The developmental time of approximately 70 and 73 days for the two specimens maintained until assisted hatching is longer than the 60-65 days developmental time taken by $A$. rotunda (Anstis et al. 2007), but as froglets were actively trying to hatch from at least 6-9 days prior to this, the time to metamorphosis may be shorter under natural conditions if development proceeded in a generally similar temperature regime to the present study. From ten days prior to hatching, the embryos were rarely fully immersed in water so that the jelly capsules could shrink, enabling the limbs of the embryos to sit much closer to the outer surface of the jelly. Despite much effort with thrusting of the limbs, neither embryo seemed able to hatch unaided and their efforts dwindled as they appeared to fatigue

The continual downward leg and arm thrusts of Metacrinia at stages 14 and 15 suggest that hatching may be initiated by this method, as occurred in $A$. 
rotunda (Anstis et al. 2007). It is possible the trigger for hatching of Metacrinia in the natural environment may be increased periods of rain, although this would fully hydrate the egg jelly and make it a much thicker barrier to the embryo. Further observations in the field are necessary to determine the trigger factors precipitating hatching.

\section{Summary}

All genera discussed here share key features typical of direct development as defined by Altig and Johnston (1989) and Altig and Crother (2006), including the lack of oral structures, adhesive glands and a spiracle, precocial development of the limbs and neural tube anatomy and a different mode of abdominal wall formation. The relatively large size of the ova and the small clutch sizes of the southwestern Australian genera are also characteristic of direct developing species (Thibaudeau and Altig 1999). Despite the presence of some characteristics shared with direct developers, including a vascular tail and dependence on yolk supply during development to metamorphosis, most of the nidicolous Australian embryos Philoria, Kyarranus and the Geocrinia rosea group differ significantly from direct developers as they have a free-living hatched tadpole stage that includes mouthparts, a spiracle, tadpole vent tube and a functional tail. The early development of the paraviviparous Rheobatrachus is not well known, but it also has a hatched tadpole stage and its vestigial spiracle and mouthparts (papillae and a non-keratinised lower jaw sheath; Tyler 1983; Anstis unpublished data) are very similar to those of the Geocrinia rosea group (Anstis unpublished data). The larval morphology of the exoviviparous Assa appears quite similar to that of the nidicolous Bryobatrachus, as both have only a mouth slit (no vestigial papillae or tadpole jaw sheaths), no spiracle, reduced fins and prominent eyes (Anstis 2002) and in these respects these two genera are most similar to the direct developing myobatrachids.

The diversity of reproductive modes in Australian anuran families (Tyler 1985, 1999; Roberts 1993), especially the Myobatrachidae, provides a wealth of material for future study. The endotrophic guilds are currently poorly known, and the evolution of these developmental patterns are not well understood. There is a good potential to provide a substantial platform for investigations into the evolutionary origins of many Australian anurans once adequate material has become available, although more data on evolutionary relationships, ecology and developmental genetics will be needed before hypotheses can be rigorously tested. However, the description presented here and in Anstis et al. (2007) move us closer to a better understanding of endotrophic life history modes.

\section{ACKNOWLEDGEMENTS}

A grant to the author for field work assistance from The Australian Biological Resources Study is gratefully acknowledged. The author sincerely acknowledges the assistance of CALM for the issue of scientific permits and Martin Dziminski for the collection of specimens, without which this study would not have been possible. Ronn Altig provided various helpful comments on the manuscript. Richard Elinson and Dale Roberts provided suggestions during the rearing of the embryos. The Western Australian Museum is also acknowledged for the loan of specimens, and the staff at the University of Western Australia provided assistance in various ways.

\section{REFERENCES}

Altig, R. and Crother, B. I. (2006). The evolution of three deviations from the biphasic anuran life cycle: alternatives to selection. Herpetological Review 37: 321-325.

Altig, R. and Johnston, G.F. (1989). Guilds of anuran larvae: relationships among developmental modes, morphologies, and habitats. Herpetological Monographs 3: 81-109.

Anstis, M., Roberts, J.D. and Altig, R. (2007). Direct development in two myobatrachid frogs, Arenophryne rotunda Tyler and Myobatrachus gouldii Gray, from Western Australia. Records of the Western Australian Museum 23: 259-271.

Barbour, T. and Loveridge, A. (1929). On some Australian toads of the genus Pseudophryne. Copeia 170: 12-15.

Blake, A.J.D. (1973). Taxonomy and relationships of myobatrachine frogs (Leptodactylidae): a numerical approach. Australian Journal of Zoology 21: 119-149.

Driscoll, D. (1998). Ground frogs on the rise. Nature Australia: Spring issue.

Frost, D.R., Grant, T., Faivovich, J., Bain, R., Haas, A., Haddad, C.F.B., de Sá, R.O., Donnellan, S.C., Raxworthy, C.J., Wilkinson, M., Channing, A., Campbell, J.A., Blotto, B.L., Moler, P., Drewes, R.C., Nussbaum, R.A., Lynch, J.D., Green, D. and Wheeler, W.C. (2006). The amphibian tree of life. Bulletin of American Museum of Natural History 297: 1-370.

Glauert, L. (1945). Some Western Australian frogs. The Australian Museum Magazine 8: 379-382.

Gosner, K. L. (1960). A simplified table for staging anuran embryos and larvae with notes on identification. Herpetologica 16: 183-190.

Harrison, L. (1927). Notes on some Western Australian frogs, with descriptions of new species. Records of the Australian Museum 15: 277-287.

Hoskin, H. J. (2004). Australian microhylid frogs (Cophixalus and Austrochaperina): phylogeny, taxonomy, calls, distributions and breeding biology. Australian Journal of Zoology 52: 237-269.

Maxson, L. R., and Roberts, J.D. (1985). An immunological analysis of the phylogenetic relationships between two enigmatic frogs, $M$. gouldii and $A$ 
rotunda. Journal of Zoology (London) 207: 289-300.

Parker, H. W. (1940). The Australasian frogs of the family Leptodactylidae. Novitates Zoologicae 42: 1-106.

Read, K., Keogh, J.S., Scott, I.A.W., Roberts, J.D. and Doughty, P. (2001). Molecular phylogeny of the Australian frog genera Crinia and Geocrinia and allied taxa (Anura: Myobatrachidae). Molecular Phylogenetics and Evolution 21: 294-308.

Roberts, J. D. (1981). Terrestrial breeding in the Australian leptodactylid frog Myobatrachus gouldii (Gray). Australian Wildlife Research 8: 451-62.

Roberts, J. D. (1984). Terrestrial egg deposition and direct development in Arenophryne rotunda Tyler, a myobatrachid frog from coastal sand dunes at Shark Bay, W.A. Australian Wildlife Research 11: 191-200.

Roberts, J. D. (1993). Natural history of the Anura. Pp. 28-34 in Glasby, C. J., Ross, G. J. B. \& Beesley, P. L. (eds) Fauna of Australia. Vol. 2A Amphibia and Reptilia. Australian Government Publishing Service, Canberra.

Thibaudeau, G., and Altig, R. (1999). Endotrophic Anurans: Development and Evolution, Pp. 170-188 in R. W. McDiarmid and R. Altig (eds) Tadpoles: the Biology of Anuran Larvae. University of Chicago Press: Chicago.
Townsend, D. S., and Stewart, M.M. (1985). Direct development in Eleutherodactylus coqui (Anura: Leptodactylidae): a staging table. Copeia 1985: 423 436.

Tyler, M. J. (1962). On the preservation of anuran tadpoles. Australian Journal of Science 25: 222.

Tyler, M. J. (1976a). A new genus and two new species of leptodactylid frogs from Western Australia. Records of the Western Australian Museum 4: 45-52.

Tyler, M. J. (1976b). Frogs. Australian Naturalist Library. Collins: Australia.

Tyler, M. J. (1983). The Gastric Brooding Frog. Croom Helm: London \& Canberra.

Tyler, M. J. (1985). Reproductive modes in Australian Amphibia, Pp. 265-267 in G. Grigg, R. Shine and H. Ehmann (eds) Biology of Australian Frogs and Reptiles. Surrey Beatty \& Sons: Sydney.

Tyler, M. J. (1999). Australian Frogs, a natural history. Reed New Holland: Sydney Australia.

Tyler, M. J., Smith, L.A. and Johnstone, R.E. (2000). Frogs of Western Australia. Western Australian Museum: Perth.

Manuscript accepted 2 July 2007 


\section{APPENDIX 1}

Measurements $(\mathrm{mm})$ of one anaesthetised specimen at stage 10 with tail outstretched, after removal from the jelly layers.

Snout-vent $=5.2$; tail length $=3.0$; body width $=3.5$; body depth $=3.0$; eye body width (measured across centre of eyes) $=2.5$; eye diameter $=1.1$; inter-orbital span $=1.1$; narial diameter (span between each inner edge of narial rim) $=0.2$; width across base of tail muscle $=0.8$; depth of tail muscle at base $=0.6$; tail depth (measured at deepest point $)=0.7$; dorsal fin depth $=0.2$; ventral fin depth $=0.2$ tail muscle depth $=0.5$ (latter three measurements in line with tail depth).

\section{APPENDIX 2}

Summary of embryo dimensions of live Metacrinia nichollsi from stages 2-15 (Townsend and Stewart 1985). Stages 23 were measured out of water and stages 4-13 were measured in water, jelly capsule measurements in bold only partly rehydrated. Dimensions in $\mathrm{mm}$, mean with range in parenthesis as follows: diameters to stage 4; snout to posterior point of curved tail in stages 5-13, including snout-vent stages 12-13; snout-vent stage 15. Dates (2006) are given as day/ month. $\mathrm{N}=$ number of specimens measured. Measurements were mostly taken daily during April, then from 3-6 day intervals during the first half of May and post hatching in early June.

\begin{tabular}{|c|c|c|c|c|}
\hline Stage & Date & $\mathbf{N}$ & Embryo Dimensions & Jelly Capsule Dimensions \\
\hline 2 & $31 / 3$ & 7 & $3.7(3.5-3.9)$ & $5.3(5.2-5.6)$ \\
\hline 3 & $1 / 4$ & 6 & $3.8(3.5-4.2)$ & $5.9(5.3-6.1)$ \\
\hline \multirow[t]{4}{*}{4} & $2 / 4$ & 11 & $3.1(3.0-3.2) \times 2.9(2.9-3.1)$ & $5.4(4.8-6.1)$ \\
\hline & $3 / 4$ & 4 & $3.9(3.6-4.2) \times 3.5(3.1-3.8)$ & $5.9(5.6-5.8)$ \\
\hline & $4 / 5$ & 4 & $3.9(3.7-4.0) \times 3.1(3.0-3.2)$ & $7.2(7.2-7.2)$ \\
\hline & $5 / 4$ & 9 & $4.2(3.0-4.7) \times 3.3(3.0-3.5)$ & $7.2(6.8-7.6)$ \\
\hline \multirow[t]{3}{*}{5} & $6-7 / 4$ & 5 & $4.3(4.0-4.5) \times 3.2(3.1-3.4)$ & $7.6(7.5-7.7)$ \\
\hline & $8 / 4$ & 9 & $4.6(4.4-4.8) \times 3.3(3.0-3.7)$ & $7.5(7.4-8.0)$ \\
\hline & $9 / 4$ & 7 & $4.6(4.3-5.0) \times 3.3(3.0-3.8)$ & $7.4(7.3-7.4)$ \\
\hline \multirow[t]{2}{*}{6} & $11 / 4$ & 9 & $5.2(4.9-5.6) \times 4.1(3.8-4.7)$ & $5.6(5.3-6.0)$ \\
\hline & $13,14 / 4$ & 8,3 & $4.4(3.7-4.5) \times 3.2(3.1-3.3)$ & $6.1(5.3-6.6)$ \\
\hline \multirow[t]{3}{*}{7} & $15 / 4$ & 5 & $4.7(4.1-5.1) \times 3.7(3.4-3.9)$ & $6.6(5.9-7.6) \times 6.4(5.8-7.3)$ \\
\hline & $16 / 4$ & 5 & $4.8(4.5-5.2) \times 3.5(3.4-3.5)$ & $7.1(6.1-7.2) \times 6.8(6.0-7.1)$ \\
\hline & $17 / 4$ & 4 & $5.2(5.0-6.1) \times 3.6(3.5-3.6)$ & $7.4(7.2-7.9) \times 7.4(7.2-7.8)$ \\
\hline 8 & $18,21 / 4$ & 4,6 & $5.4(5.0-5.8) \times 3.8(3.5-4.2)$ & $7.5(7.1-8.1) \times 7.4(6.9-7.9)$ \\
\hline \multirow[t]{2}{*}{9} & $23,24 / 4$ & 5,5 & $5.4(4.8-6.0) \times 3.0(2.9-3.1)$ & $7.5(6.6-8.7) \times 7.4(6.4-8.7)$ \\
\hline & $25 / 4$ & 4 & $5.6(5.0-5.8)$ & $7.9(6.4-8.7) \times 7.7(6.3-8.7)$ \\
\hline \multirow[t]{2}{*}{10} & $29 / 4$ & 3 & $5.8(5.6-6.0)$ & $8.7(8.5-8.7) \times 8.6(8.5-8.7)$ \\
\hline & $30 / 4$ & 3 & $6.1(5.5-6.4)$ & $9.1(8.9-9.3)$ \\
\hline 11 & $2 / 5$ & 3 & $6.1(5.6-6.3)$ & $9.0(8.1-8.4)$ \\
\hline 12 & $8 / 5$ & 2 & $6.1,5.6(\mathrm{SV}=5.5,4.8)$ & \\
\hline \multirow[t]{2}{*}{13} & $14 / 5$ & 2 & $5.8,5.5$ & \\
\hline & $16 / 5$ & 2 & $8.4,8.1(\mathrm{SV}=6.3,5.6)$ & \\
\hline \multirow[t]{2}{*}{15} & $3 / 6$ & 1 & 6.4 & \\
\hline & $6 / 6$ & 1 & 6.3 & \\
\hline
\end{tabular}

